\title{
Polypyrrole Soft Actuators
}

\author{
Yasushiro Nishioka \\ College of Science and Technology/Nihon University \\ Japan
}

\section{Introduction}

Organic soft actuators attract strong attentions because they have many advantages compared to conventional mechanical actuators. Organic soft actuators are generally light and flexibly deformed. In addition, they operate under low voltage ranges as low as 1 volt or so, and generate no sound during deformation. Amongst those soft actuators, bending soft actuators are of special interest because small volume change in organic materials can cause a large bending displacement. For example, soft actuators consisting of Ionic Conducting Polymer Films (ICPF) have been widely used as bending actuators (Guo et al., 1996). However, the fabrication processes for ICPF actuators seem complicated. In contrast, polypyrrole films synthesized using electropolymerization as a new material for organic soft actuators have been extensively studied (Hara et al., 2004a, 2004b, Hatchison et al., 2000, Jager et al., 1999). In addition, the amount of the volume change can be modified by altering the electropolymerization conditions. Hara et. al. recently reported that the expansion and contraction ratio of their polypyrrole actuators exceeded $40 \%$, which is very encouraging (Hara et al., 2005). Bending actuators can be easily fabricated by forming a bimorph structure consisting of a polypyrrole film and other film material.

In this section, simple bimorph actuators using an electropolymerized polypyrrole (PPy) film and a both-side adhesive tape were fabricated. It turned out that those actuators nonuniformly bent depending on the distance between the actuator and the counter electrode. We fabricated a structure consisting of polypyrrole/both-side adhesive tape/polypyrrole whose two polypyrrole films have different extension/contraction ratios, and found that the actuator exhibited more uniform bending deformation which was nearly independent of the distance between the electrodes.

\subsection{Principle of PPy actuator}

Figure 1.1. describes the principle of the PPy actuator functions. A PPy actuator and a counter electrode are placed in an electrolysis solution. When a negative voltage is applied to the actuator, negative ions in the solution will be driven out from the actuator, the actuator shrinks. This is called dedoping process. When positive voltage is applied to the actuator, the negative ions are absorbed into the PPy actuator (doping process), and the actuator expands. The conductive PPy polymer networks are loosely dangled, and the spacing between the polymer chains can expand and shrink during the doping and dedoping processes. 


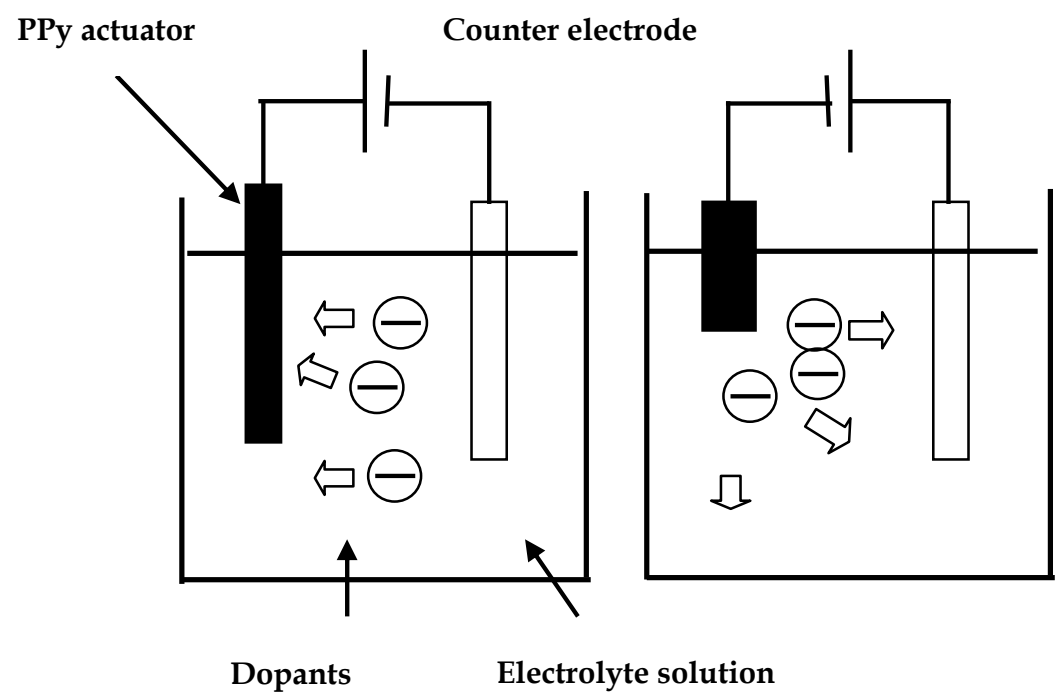

(a)

(b)

Fig. 1.1. The conceptual description of principle for the expansion and contraction processes of PPy actuators.

\subsection{Experimentals}

\subsubsection{Galvanostatic electropolymerization of pyrrole}

Figure 1.2. describes the experimental setup for the Galvanostatic electropolymerization to form PPy films. A counter electrode (Ti), a reference electrode $(\mathrm{Ag} / \mathrm{AgCl})$, and a working electrode ( $\mathrm{Ti}$ ) were immersed into a solvent containing pyrrole monomers and an electrolyte, and the bias voltage was controlled to keep constant current between the counter electrode and the working electrode during the PPy polymerization. The PPy film deposited on the working electrode was peeled off, and was used as an actuator material. The characteristics of PPy polymers had very different characteristics influenced by different synthetic conditions of the galvanostatic electropolymerization. For example, if different electrolytes were used, the expansion contraction ratios were very different (Han et al., 2004). The polymerization was done using a computer controlled potentiostat (HZ-5000, Hokuto Denko Corp.).

Here, PPy films with different expansion/contraction behaviors were prepared under different fabrication conditions (PPy1 and PPy2) listed below.

a. PPy1; Electrolyte: N.N-Diethyl-N-methyl-N-(2-methoxyethyl) ammoniumbis (trifluoro methane slfonyl) imide, Solvent: Methyl Benzoate, Room temperature, Current: 0.55 $\mathrm{mA} / \mathrm{cm}^{2}$, Deposition time: $4 \mathrm{hrs}$ )

b. PPy2; Electrolyte: tetra- $n$-butylammonium trifluoromethanesulfonate $\left(\mathrm{TBACF}_{3} \mathrm{SO}_{3}\right)$, Solvent: Methyl Benzoate, Room temperature, Current: $0.50 \mathrm{~mA} / \mathrm{cm}^{2}$, Deposition time: 2hrs)

Here, two films with the thickness of $68.8 \mu \mathrm{m}$ and $138.8 \mu \mathrm{m}$ were prepared under the PPy1 conditions, and a film with the thickness of $28.6 \mu \mathrm{m}$ was prepared under the PPy2 
conditions. The thicknesses of the PPy films were measured using a micrometer. Three samples of $\operatorname{PPy} 1(68.8 \mu \mathrm{m}) /$ adhesive tape, $\operatorname{PPy} 1(138.8 \mu \mathrm{m}) /$ adhesive tape, and PPy1(138.8 $\mu \mathrm{m}) /$ adhesive tape/PPy2 $(28.6 \mu \mathrm{m})$ were fabricated. The PPy film and the adhesive tape film were stacked together. The stacked structure was cut to form actuators with the appropriate size. The area of the samples investigated here was $5 \times 20 \mathrm{~mm}^{2}$. The adhesive tape used here is a both-side adhesive tape (NW-10S) produced by Nichiban Inc.

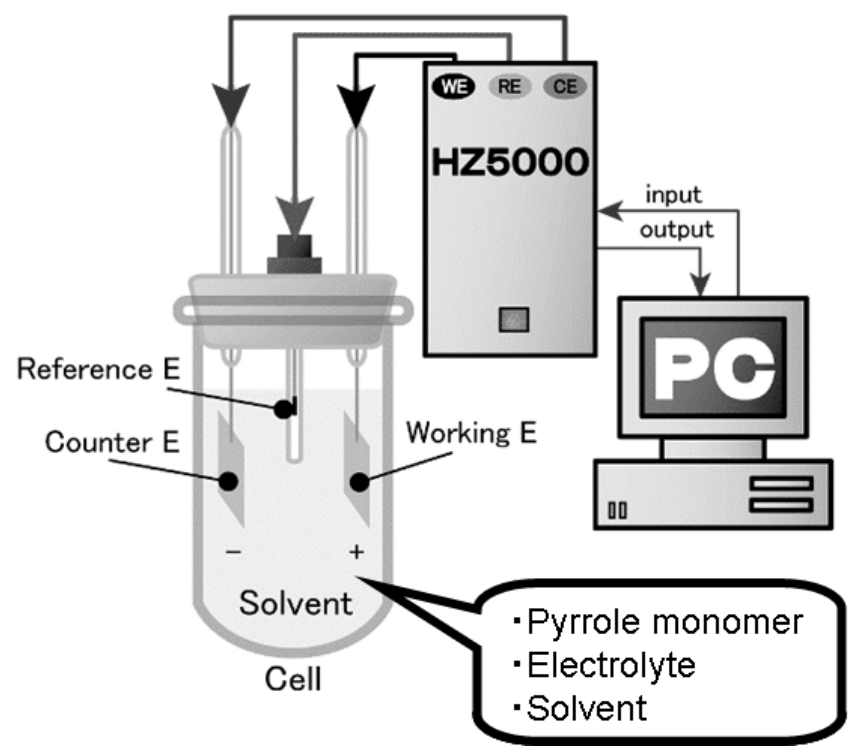

Fig. 1.2. Setup for Galvanostatic electropolymerization.

\subsubsection{Actuator characterizations}

The bending experiments for the fabricated devices were performed using the same experimental setup for the PPy polymerization as shown in Fig. 1.2. Here, the potentiostat HZ-5000, Hokuto Denko Corp. was also used to perform the actuation experiments. The top part of the PPy actuator was connected to the working electrode using a metal clip to make the electrical contact. Then, the counter electrode, the reference electrode, and the the actuator were immersed in a water solution of an electrolyte, lithium bis-trifluoromethane sulphonyl imide (LiTFSI). A bias voltage was given at the working electrode during the bending experiments. The bias ranges was $-1.0 \sim+1.0 \mathrm{~V}$, and the bias sweep rate was 10 $\mathrm{mV} / \mathrm{s}$. Please note that only the lower part of the actuator was immersed in the LiTFSI solution, and that the conducting PPy actuator acts as the working electrode.

\subsubsection{Results and discussions}

Figure 1.3a and figure 1.3b show the photographs during deformation of the PP1(68.8 $\mu \mathrm{m}) /$ adhesion tape actuator. Obviously, the bi-directional bending of the actuator was observed. However, as seen in the Fig. 1.3a, the actuators edge area close to the counter electrode shows a curl, and the actuator bending was not uniform. 


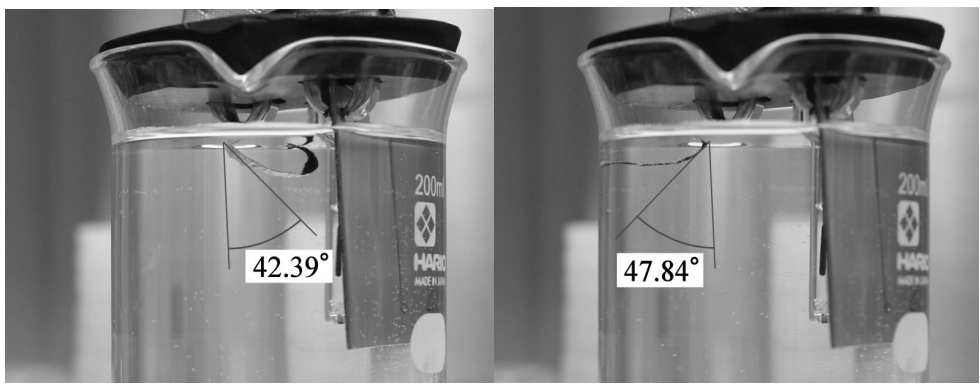

(a)

(b)

Fig. 1.3. Bi-directional bending organic actuator of PPy1 $(68.8 \mu \mathrm{m}) /$ adhesive tape.

This phenomenon may be due to the fact that the electric field between the actuator and the counter electrode increases resulting in the increase of the ionic current when the actuator comes closer to the counter electrode. Therefore, it was considered that some techniques to prevent this phenomenon were necessary. It was considered that if PPy1/adhesive tape/PPy2 with different extension/contraction ratios or different thickness may prevent non-uniform bending of the actuators. Figure 1.4. exhibits the bending characteristics of the PPy1 $(138.8 \mu \mathrm{m}) /$ both-side adhesive tape/PPy2 $(38.8 \mu \mathrm{m})$. Note that the actuator shown in Fig. 1.4. shows fairly uniform bending independent of the relative positions from the counter electrodes with some expense of the bending angle.

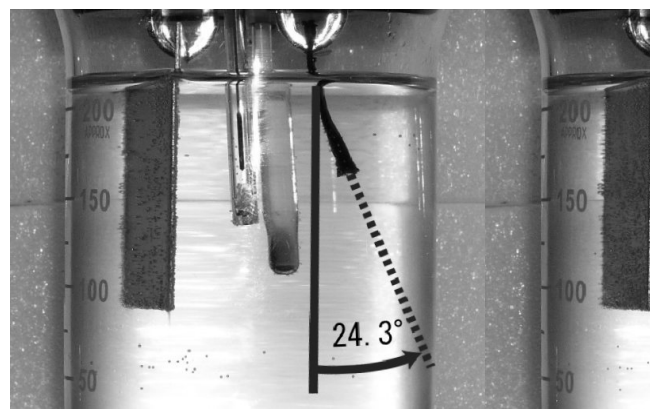

(a)

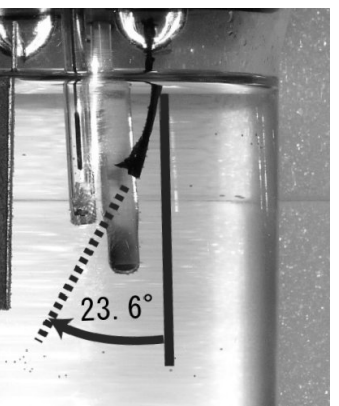

(b)

Fig. 1.4. Bi-directional bending organic actuator of PPy1(138.8 $\mu \mathrm{m}) /$ adhesive tape/PPy2(28.6 $\mu \mathrm{m})$.

The experimental results are summarized in Table.1. As seen in Table.1, the bending angle increases when the PPy film thickness increases, and the bending angle can be adjusted by changing the thicknesses of the PPy films on both sides.

The reason for the uniform bending has still not yet been clarified. However, it might be speculated that when a part of the actuator comes closer to the counter electrode, the amount of dopants penetrating into the part will be larger, which may cause the nonuniform bending of the PPy/adhesive actuator. On the other hand, this nonuniform bending may be canceled in the PPy1/adhesive tape/PPy2 structure, because the amounts of the dopants of the PPy1 and the PPy2 films near the counter electrode become larger simultaneously. 


\begin{tabular}{|c|c|c|c|c|}
\hline \multicolumn{2}{|c|}{ Thickness $(\mu \mathrm{m})$} & \multirow{2}{*}{\multicolumn{2}{|c|}{ Bending angle (deg) }} & \multirow[b]{2}{*}{ Total (deg) } \\
\hline $\begin{array}{l}\text { PPy1 (counter } \\
\text { electrode side) }\end{array}$ & PPy2 (Rear side) & & & \\
\hline 68.8 & None & +42.4 & -47.8 & 90.2 \\
\hline 138.8 & None & +11.3 & -85.4 & 96.7 \\
\hline 138.8 & 28.6 & +24.3 & -23.6 & 47.9 \\
\hline
\end{tabular}

Table 1. Results of bending angles of the PPy actuators $\%$ Positive angle means that actuators bend towards direction opposite to the counter electrode.

\subsection{Conclusion}

Two kinds of polypyrrole films were galvanostatically fabricated, and the polypyrrole/adhesive bending actuators were fabricated. The actuators exhibited a large bending angle range of nearly $90^{\circ}$. However, when the actuators approached the counter electrode, the bending angle increased which resulted in non-uniform bending of the actuators. Then, the three-layered actuator of PPy1/adhesive tape/PPy2, whose PPy films have different expansion/contraction ratios, was fabricated and characterized. The three layered actuator showed pretty uniform bending deformation with some expense of the bending angle.

\section{Polypyrrole soft actuator having corrugated structures}

\subsection{Introduction}

PPy actuators have been regarded as a possible candidate for an artificial muscle because the generation of stress is nearly ten times larger than human muscles. However, the expansion and contraction ratio of a PPy actuator was only 1-3\% which was far smaller than the value of human muscle, 25\% (Hara et al., 2005, Baughman, 1996). However, Hara et. al. recently reported that an expansion and contraction ratio of their PPy actuators exceeded $40 \%$, which is very encouraging (Hara et al., 2004). There are also several reports to improve the expansion and contraction ratios by modifying PPy film deposition conditions such as temperatures and modifying supporting electrolyte solutions (Hara et al., 2005a, 2005b, 2005c, Zama et al., 2005a, 2005b, Ogasawara et al., 1986).

In this section, a new structure of PPy actuators to improve the expansion and contraction ratio is proposed. Here, the details of fabrication procedures and the characterization results of the corrugated PPy soft actuator are reported.

\subsection{Experimentals}

\subsubsection{Fabrication processes of PPy soft actuator}

The PPy thin film was fabricated by electropolymerization. The electropolymerization of PPy was done in a methyl benzoate solution with a volume of $50 \mathrm{ml}$ in which pyrrole monomers with a concentration of $0.25 \mathrm{~mol} \mathrm{dm}^{-3}$ and the electrolyte $(\mathrm{N}, \mathrm{N}-$ Diethyl- Nmethyl-N-(2-methoxyethyl) ammonium bis (trifluoromethanesulfonyl) imide with a concentration of $0.2 \mathrm{~mol} \mathrm{dm}^{-3}$ are dissolved.

The working electrode was a Au thin film sputtered on an acrylic board and the counter electrode was a Ti plate. The area of the electrodes immersed in the solvent was $30 \times 25 \mathrm{~mm}^{2}$. The polymerization was done at a constant current of $0.2 \mathrm{~mA} \mathrm{~cm}^{-2}$ for $4 \mathrm{hrs}$ at the room temperature. The PPy thin film was polymerized with the doped anions in the supporting 
electrolyte. The PPy thin film was then peeled off from the electrode, and it was used as an actuator.

A working electrode with a corrugated structure and a plane structure were used for fabricating PPy thin film having the corrugated structure and the plane structure. Figure 2.1. describes the process to fabricate the corrugated PPy actuator. The corrugated working electrode was made by the following methods. Firstly, an acrylic board was processed to form a corrugated structure which had the ditches of $1 \mathrm{~mm}$ in depth, and spacing between the ditches was $5 \mathrm{~mm}$ as seen in Fig. 2.1. Next, the Au thin film was coated on the processed surface of the acrylic board by sputter deposition. PPy was polymerized on the acrylic board covered by the Au thin film which worked as a working electrode. Then, the corrugated PPy thin film was peeled off from the electrode by dissolving the acrylic board in acetone. The PPy thin film was cut into slices with the width of $6 \mathrm{~mm}$, and these were used as actuators. PPy films without the corrugated structure were also fabricated on the plane acrylic board with the Au film for comparison. The thicknesses of the PPy films were measured using a micrometer, and these are approximately $14.5 \mu \mathrm{m}$ for both of the corrugated PPy film and the plane PPy film.

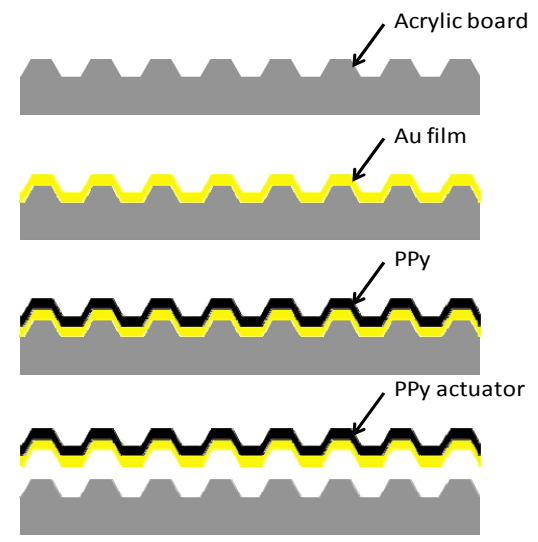

Fig. 2.1. Conceptual description of the corrugated PPy actuator fabrication process.

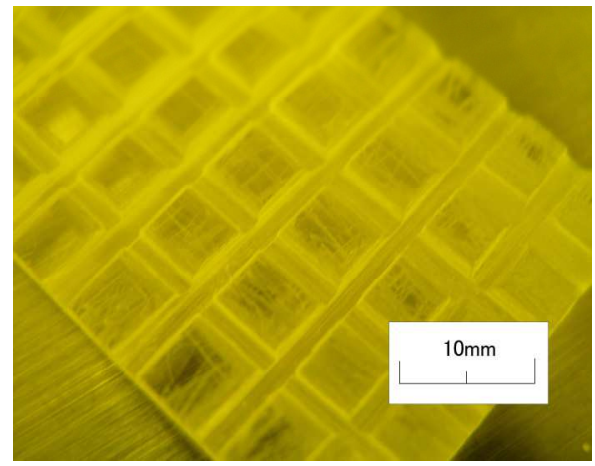

Fig. 2.2. Optical microscope image of the surface of the corrugated acrylic board. 
Figure 2.3a. and 2.3b. show the scanning electron microscope (SEM) images for the PPy films formed on the corrugated working electrode and the plane working electrode, respectively. The surfaces of the both PPy films look like a sponge surface. However, no notable differences were observed between the two films.

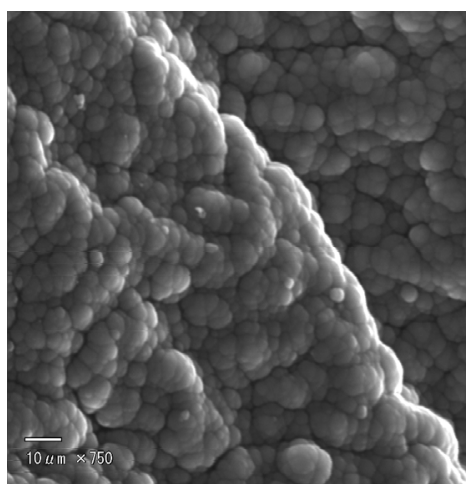

(a)

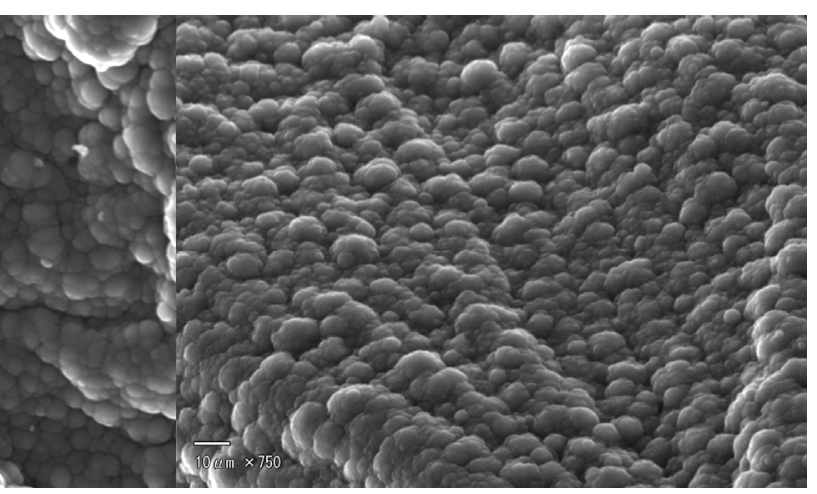

(b)

Fig. 2.3. Scanning electron microscope images of the PPy surfaces formed on the corrugated working electrode (a), and the PPy surface formed on the plane working electrode (b).

\subsubsection{Characterization of PPy soft actuator}

Figure 2.4. shows the actuator characterization system which utilizes a balance to measure the expansion and contraction ratios. The PPy actuator was used as a working electrode in the LiTFSI solution of $1 \mathrm{~mol} \mathrm{dm}^{-3}$, and the both of PPy actuator edges were suspended by

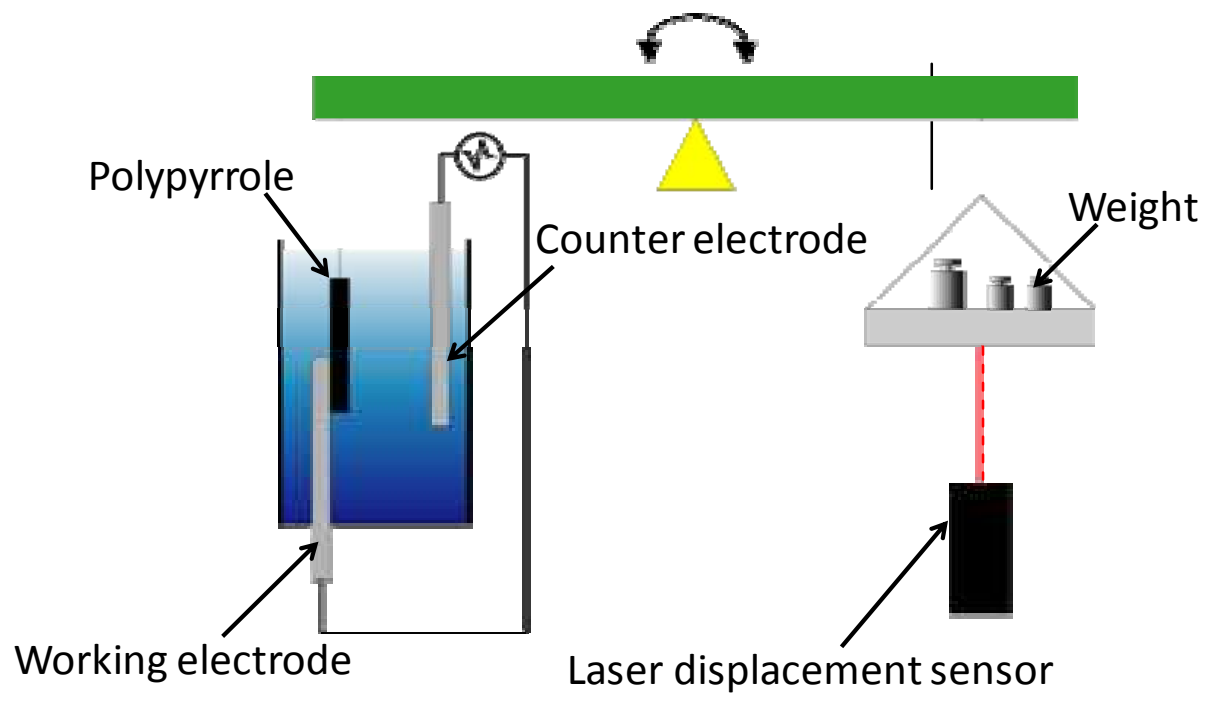

Fig. 2.4. Conceptual description of experimental setup for measuring the expansion and contraction ratio of PPy actuators. 
clips. The size of the moving part of the PPy actuators was $6 \mathrm{~mm}$ in width, $23.8 \mathrm{~mm}$ in length, and $14.5 \mu \mathrm{m}$ in thickness. The PPy actuator exhibited the expansion and contraction motions under the altering bias with the triangular wave shape applied between the PPy actuator and the counter electrode. The peak values of the bias voltage were $-1 \mathrm{~V}$ and $+1 \mathrm{~V}$, and the bias voltage sweep rate was $20 \mathrm{mVs}^{-1}$. The extension and contraction of the PPy actuator was measured by monitoring the displacement of the weight position using a laser displacement sensor. Moreover, an arbitrary load stress was applied on the PPy actuator by putting weights on the saucer of the balance. The weight on saucer was adjusted so that the stress to the cross section of the PPy actuator was $0.3 \mathrm{MPa}$. The reason for selecting the stress of $0.3 \mathrm{MPa}$ was that the generated stress of human muscle is $0.3 \mathrm{MPa}$. Hereafter, the expansion and contraction ratio is defined as the actuator length change divided by the initial length.

\subsection{Result and discussion}

The expansion and contraction ratios of the corrugated PPy actuator and the plane PPy actuator were compared during a bias cycle between $-1 \mathrm{~V}$ and $+1 \mathrm{~V}$ at the sweep rate, 20 $\mathrm{mVs}^{-1}$ as shown in Fig. 2.5. The expansion ratio of the corrugated actuator, $6.6 \%$ was larger than that of the plane actuator, $3.1 \%$. However, the contraction ratios of these actuators are nearly the same. The full swing of the expansion and contraction ratio of the corrugated PPy actuator was $11.6 \%$, while that of the plane (normal) PPy actuator was $8.1 \%$. In addition, the response time of the corrugated PPy actuator is notably shorter than that of the plane PPy actuator.

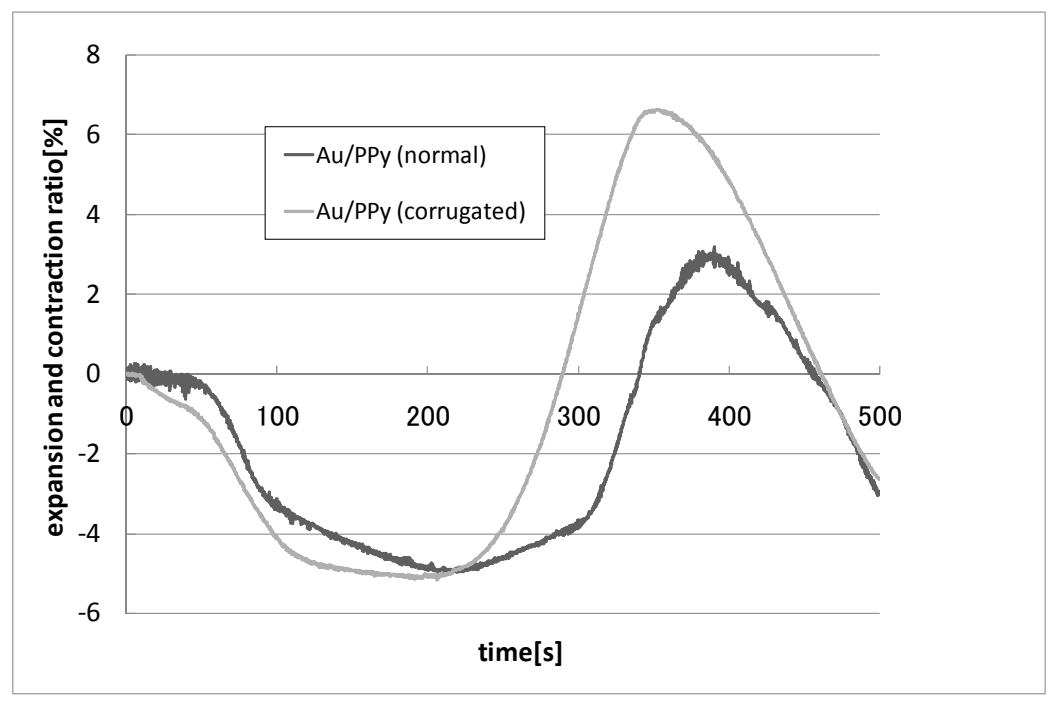

Fig. 2.5. Comparison of the expansion and contraction ratios of the corrugated PPy actuator and the plane PPy actuator during one bias cycle (sweep rate $20 \mathrm{mVs}-1$ between $-1 \mathrm{~V}$ and $+1 \mathrm{~V})$. 
The reason for the increase of the expansion ratio of the corrugated PPy actuator has not yet been clarified. One possible cause for that is that the corner parts of the corrugated PPy actuators expands and become more flat, and another cause is that the corrugated PPy film surface area is larger than that of the plane PPy surface. This is because the amount of the absorbed dopants in the corrugated actuator was larger than that of the plane PPy.

The behaviors of the expansion and contraction for the repeated 15 bias cycles are also shown in Fig. 2.6. The peak and bottom values of the expansion and contraction ratios of both of the PPy actuators continued to increase as the cycle numbers increases. It is clear that the creep or memory effect is observed. In other word, the total length of the both actuators continued to increase. It should be also noted that the difference between the peak value and the bottom values becomes smaller in the plane actuator, while that of the corrugated actuator remains the same level. The mechanisms for the different behaviors of those PPy actuators are not clear. However, the corrugated PPy actuator seems to have better performances than those of the plane PPy actuator.

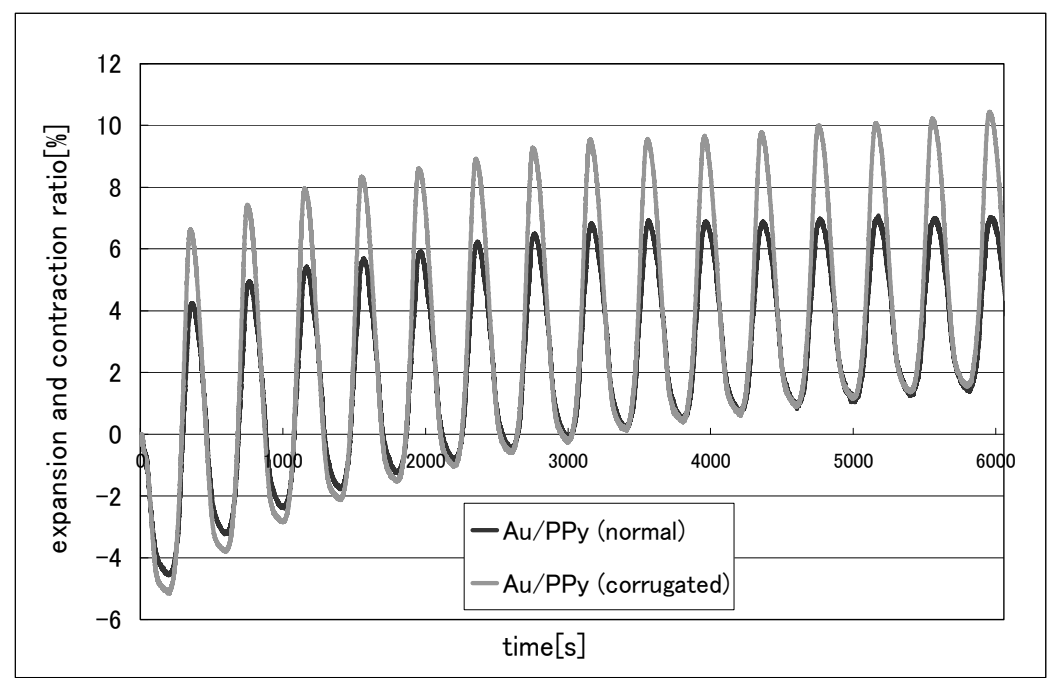

Fig. 2.6. Expansion and contraction of the PPy actuators during 15 biasing cycles. The bias voltage range was between $-1 \mathrm{~V}$ and $+1 \mathrm{~V}$, and the voltage sweep rate was $20 \mathrm{mVs}-1$.

\subsection{Conclusion}

The corrugated PPy actuator was fabricated using the electropolymerization method. The PPy film was deposited on the Au film deposited corrugated acrylic board which worked as a working electrode during the electropolymerization. The acrylic board was then etched off to release the actuator structure. The fabricated corrugated PPy actuator exhibited the larger total swing of the expansion and contraction ratio of $11.6 \%$, while that of the plane (normal) PPy actuator exhibited $8.1 \%$. Although the creep effects was observed in the both type of the PPy actuators, the total swing of the expansion and contraction ratio remained at the similar level in the corrugated PPy actuator, and that of the plane (normal) PPy actuator continued 
to decrease within the voltage swing $(-1 \mathrm{~V}$ to $+1 \mathrm{~V})$ for 15 cycles. Thus, it may possible to conclude that the corrugated PPy actuator have better performances than those of the plane PPy actuator.

\section{Effect of 2-propanol concentration in electrolyte solution on polypyrrole actuator performance}

\subsection{Introduction}

Recently, it has been reported that some PPy actuators exhibit strains of more than $10 \%$, and that some of those even achieved strains of up to $40 \%$ (Hara et al., 2004). The improved strain has been mostly achieved using an electrolyte of tetra-n-butylammonium bis(trifluoromethansulfonyl)imide (TBATFSI) during PPy electropolymerization. These actuators generally function under a low potential voltage range less than $1 \mathrm{~V}$.

Hara et al. reported that their TFSI-doped porous PPy films exhibited increased deformation when their aqueous lithium bis(trifluoromethansulfonyl)imide (LiTFSI) electrolyte solutions contained propylene carbonate (Hara et al., 2004). They attributed those effects to the swelling of the PPy film caused by the penetration of propylene carbonate. The swelled PPy film could more easily pass TFSI anions. We also immersed TFSI-doped PPy films into several organic chemicals, and found that the PPy films showed notable swelling in 2propanol (Hoshino et al., 2011). Therefore, it was interesting to investigate whether the PPy actuators show improved deformation behaviors in aqueous LiTFSI solutions containing 2propanol. In this section, the electrochemical deformation characteristics of TFSI-doped PPy soft actuators in aqueous LiTFSI solutions with different 2-propanol concentrations are reported.

\subsection{Experimental procedure}

The polymerization of PPy films was carried out using a computer-controlled potentiogalvanostat (Hokuto Denko HZ-5000). A counter electrode (Ti), a reference electrode $(\mathrm{Ag} / \mathrm{AgCl})$, and a working electrode $(\mathrm{Ti})$ were immersed into methyl benzoate solutions of $0.25 \mathrm{M}$ pyrrole and $0.2 \mathrm{M} \quad \mathrm{N}, \mathrm{N}$-diethyl-N-methyl-N-(2-methoxyethyl)ammonium bis(trifluoromethanesulfonyl)imide, and the potential voltage was controlled to keep a constant current of $0.2 \mathrm{mAcm}^{-2}$ for $4 \mathrm{~h}$ at $20{ }^{\circ} \mathrm{C}$ between the counter electrode and the working electrode. The thickness of the PPy films was measured to be approximately 150 $\mu \mathrm{m}$ using a micrometer. The obtained films were peeled off from the electrode, rinsed with acetone, and dried in air. The PPy films were cut into $20 \times 5 \mathrm{~mm}^{2}$ strips to form the PPy actuators.

The actuator characterization system that utilizes a balance to measure the expansion and contraction ratios under load stress was described in Fig. 2.4. (Morita et al., 2010, Chida et al., 2010). The PPy actuator was used as the working electrode in the $1 \mathrm{M}$ LiTFSI aqueous electrolyte solutions containing 2-propanol at various concentrations of $0,20,30,40,60,80$, and $100 \%$. Both of the PPy actuator ends were clipped with two metal plates. The PPy actuator exhibited the expansion and contraction motions under the alternating potential with the triangular wave shape applied between the PPy actuator and the counter electrode. The potential voltage difference between the PPy actuator and the electrolyte solution was monitored using the $\mathrm{Ag} / \mathrm{AgCl}$ reference electrode. The peak values of the potential voltage 
were -1 and $+1 \mathrm{~V}$, and the potential sweep rate was $10 \mathrm{mVs}^{-1}$. The extension and contraction of the PPy actuator was measured by monitoring the displacement of the weight position using a laser displacement sensor (Keyence LE-4000). Moreover, a load stress of $0.3 \mathrm{MPa}$ was applied on the PPy actuator by placing corresponding weights on the saucer of the balance.

\subsection{Results and discussion}

Figure 3.1a shows the time dependences of the strain of the actuators, as measured by the displacement of the weight as a function of time under a load stress of $0.3 \mathrm{MPa}$. The strain in Fig. 3.1a is defined as the length change of the PPy actuators divided by the length prior to deformation. No potential voltage was given for the first $30 \mathrm{~s}$, and after that repeated voltage sweeps with a period of $400 \mathrm{~s}$ were applied to the PPy actuators, as shown in Fig. 3.1b. The characteristics of the actuators were measured in aqueous solutions of LiTFSI with different 2-propanol concentrations of 0, 20, 80, and 100\%. During the initial $130 \mathrm{~s}$ of the first cycle, the PPy actuators immersed in the electrolyte solutions with 2-propanol concentrations of 0 and $20 \%$ showed slight reduction of the PPy length. Notable actuator elongation of approximately 3.5\% due to swelling was observed in the electrolyte solutions with the 2-propanol concentrations of 80 and 100\% even when the PPy potential was negative for the first $130 \mathrm{~s}$. In this case, there should be no penetration of TFSI- anions into the PPy actuators. This may be due to the fact that neutral 2-propanol molecules penetrate into the PPy porous structures resulting in the elongation of the actuators (swelling) under stress.

Here, it should be noted that the strain of the measured PPy actuator consists of the electrochemical strain caused by anion motions and the swelling (creeping) strain. Therefore, the electrochemical strain is defined by the difference in the peak value minus the lowest value of the strain for each potential cycle. The electrochemical strain of the PPy actuator driven in the $0 \%$ 2-propanol electrolyte for the second cycle was nearly $3 \%$. In contrast, the electrochemical strain of the PPy actuator driven in the aqueous solution of LiTFSI containing 20\% 2-propanol was increased up to $12 \%$. However, the electrochemical strain of the actuator driven in the LiTFSI solution of $80 \%$ 2-propanol became nearly $5 \%$, and it continued to decrease as time elapsed. In this case, the maximum strain of the PPy actuator stayed at approximately $12.5 \%$, but the minimum strain of the actuators continuously increased. The electrochemical strain of the actuator driven in the LiTFSI solution of $100 \%$ 2-propanol decreased to $2 \%$. Here, the creeping effect seems to dominate, but the electrochemical strain is suppressed. This may be due to the fact that the ionic conductivity of the LiTFSI electrolyte solution is much smaller than that of the aqueous solution. The minimum strain of the actuator continues to increase as time elapses. This behavior appears to be similar to the creeping effect in metal deformation processes. Sendai et al. recently reported their detailed study on the creeping effect of PPy actuators, and concluded that this elongation could be recovered by releasing the stress during the deformation [15]. Hence, they called this phenomenon the memory effect.

Figure 3.2. shows the 2-propanol concentration dependence of the electrochemical strain. Note that the electrochemical strain of the PPy actuators shows the maximum at a 2propanol concentration between 20 and $40 \%$. Since this 2-propanol concentration range is fairly wide, slight change in the 2-propanol concentration may not affect the performance of the PPy actuators. 


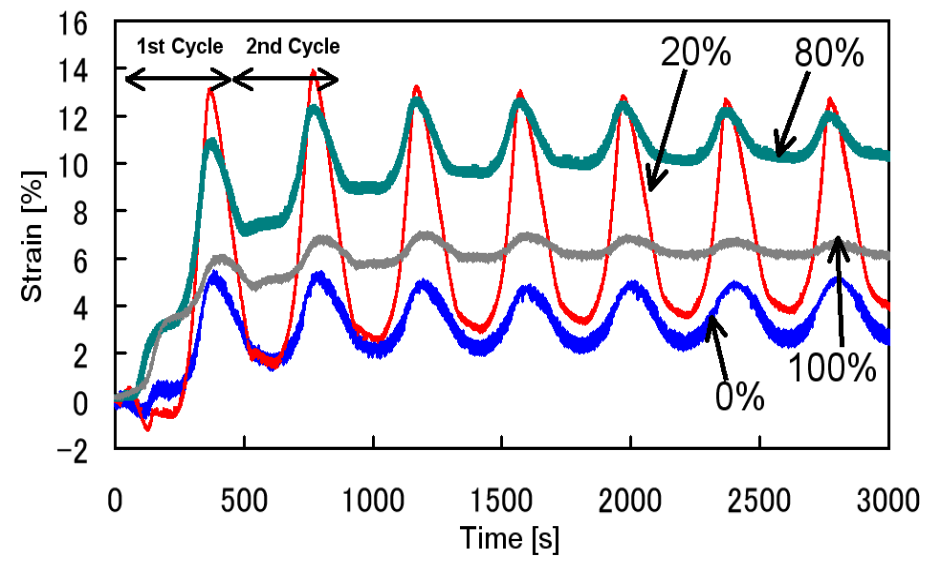

(a)

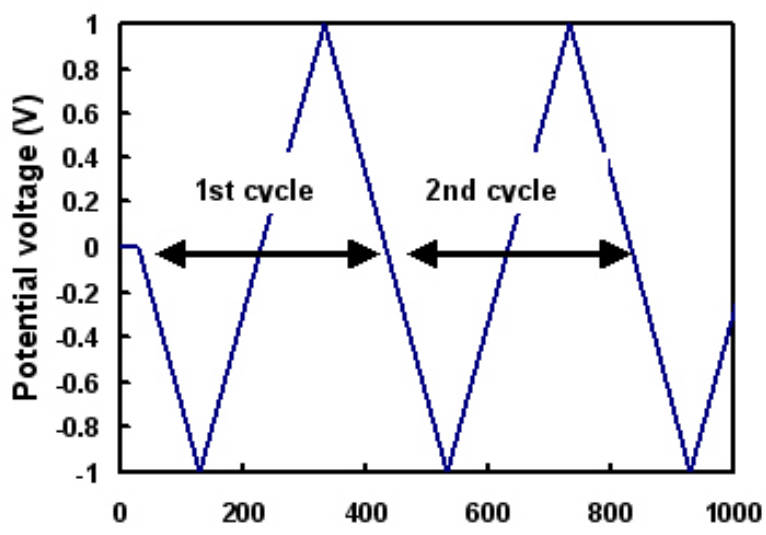

Time (s)

(b)

Fig. 3.1. (a) Relationship between the strain of the actuator and time under the repeated operation of the actuator for 8 times. The actuators were electrochemically deformed in aqueous solutions of $1 \mathrm{M}$ LiTFSI mixed with 2-propanol concentrations of $0,20,80$, and $100 \%$. The load stress during the deformation was $0.3 \mathrm{MPa}$. (b) Potential voltage shape shown as a function of time. The potential voltage during the first $30 \mathrm{~s}$ was maintained at 0 $\mathrm{V}$, and no stress was applied. A stress of $0.3 \mathrm{MPa}$ was applied after $30 \mathrm{~s}$. 


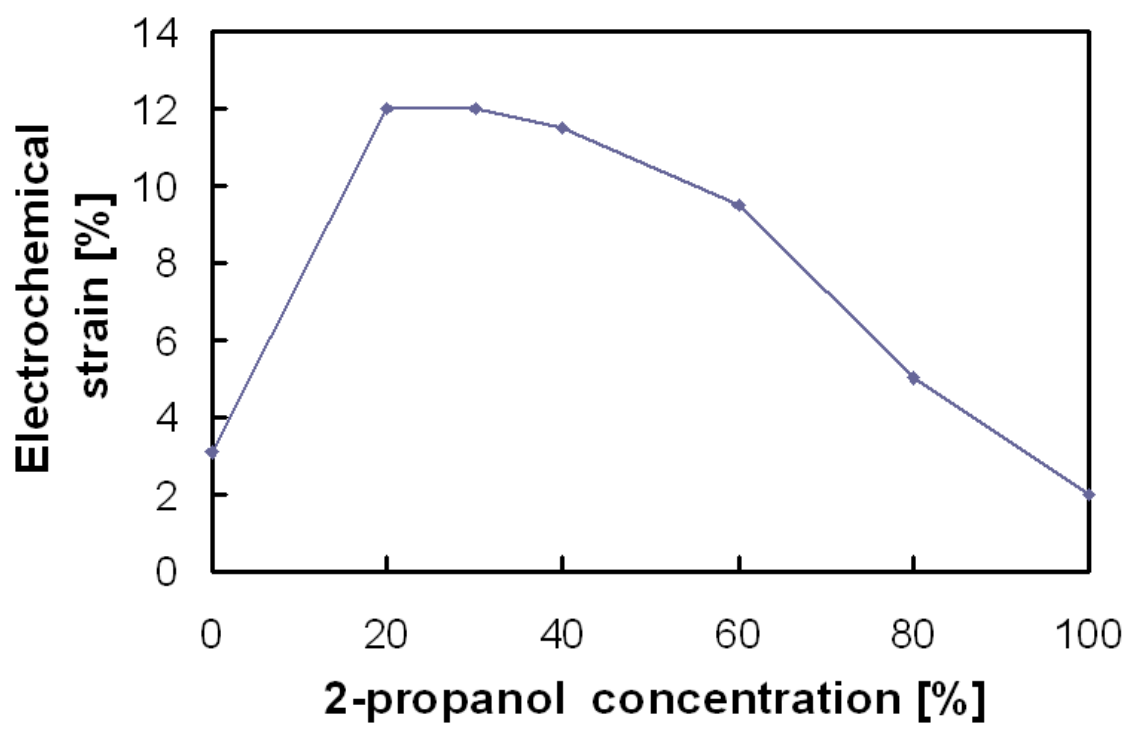

Fig. 3.2. Relationship between the electrochemical strain and the 2-propanol concentration of LiTFSI electrolyte solutions.

Figure 3.3. shows comparisons of (a) the potential voltage dependences of the strain of the second cycle for the PPy actuators deformed in the electrolyte solutions with 0 and $20 \% 2$ propanol concentrations, and (b) the potential voltage dependence of the ionic current flowing into the PPy actuators for the second cycles. The curve (b) is called a "cyclic voltammogram (CV)". When the current increases, the PPy actuator expands. This corresponds to the anion (TFSI-) penetration into the positively biased PPy actuator. In contrast, $\mathrm{Li}^{+}$cations will penetrate into the PPy film when the actuator is negatively biased. However, the diameter of the cations is much smaller than that of TFSI- anions. Thus, the elongation during the negative bias should be negligibly small. It is clear that both $\mathrm{CV}$ characteristics corresponding to the 0 and 20\% 2-propanol concentrations suggest that the deformation of the PPy actuator is due to the penetration of the TFSI- anions. The electrochemical strain is much larger for the PPy actuator driven in the 20\% 2-propanol electrolyte solution than that in the 0\% 2-propanol electrolyte solution. As shown in Fig. 3.3.b, the hysteresis of the PPy actuator in the 20\% 2-propanol electrolyte is much larger than that in the $0 \%$ 2-propanol electrolyte. This means that the number of TFSI- ions penetrating into the PPy actuator and out diffusing from that in the 20\% 2-propanol electrolyte solution is much larger than that in the $0 \%$ 2-propanol electrolyte solution, which explains the increased deformation of the PPy actuator in the 20\% 2-propanol electrolyte solution.

Figure 3.4. shows a comparison of the CV characteristics of the PPy actuators deformed in the LiTFSI aqueous solutions with the 2-propanol concentrations of 30,40,60, 80, and 100\%. The large hysteresis was maintained for the CV curves for 20 [Fig. 3.3.b], 30, and 40\%. These $\mathrm{CV}$ curves became smaller as the concentration of 2-propanol increases above $60 \%$. Both cation and anion currents are suppressed, possibly due to the reduced ionization ratio of LiTFSI in the 60, 80 and 100\% 2-propanol solutions, which explains the reduced deformation range above $60 \%$. 


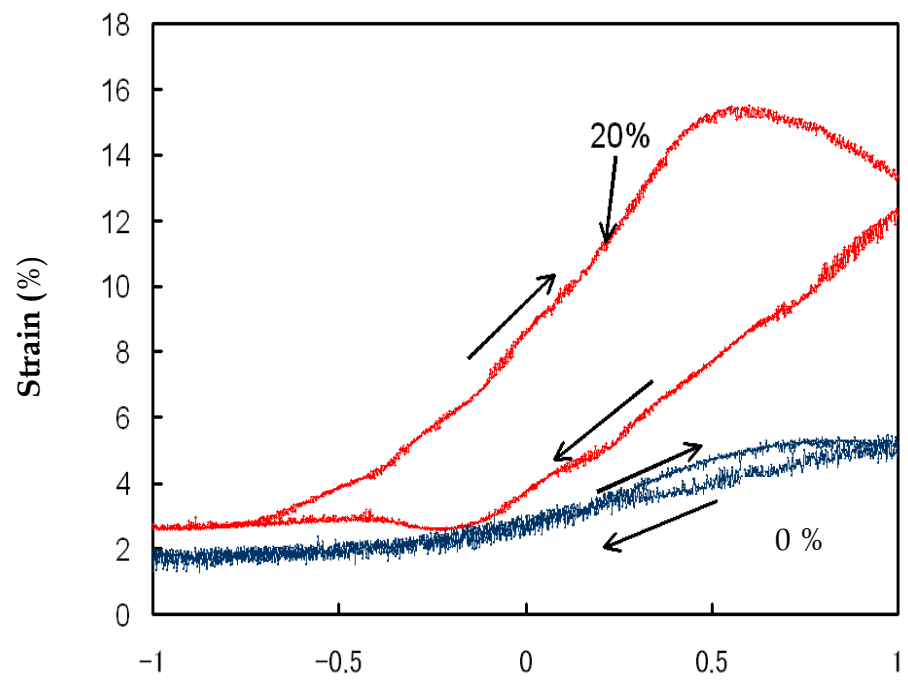

Potential voltage (V)

(a)

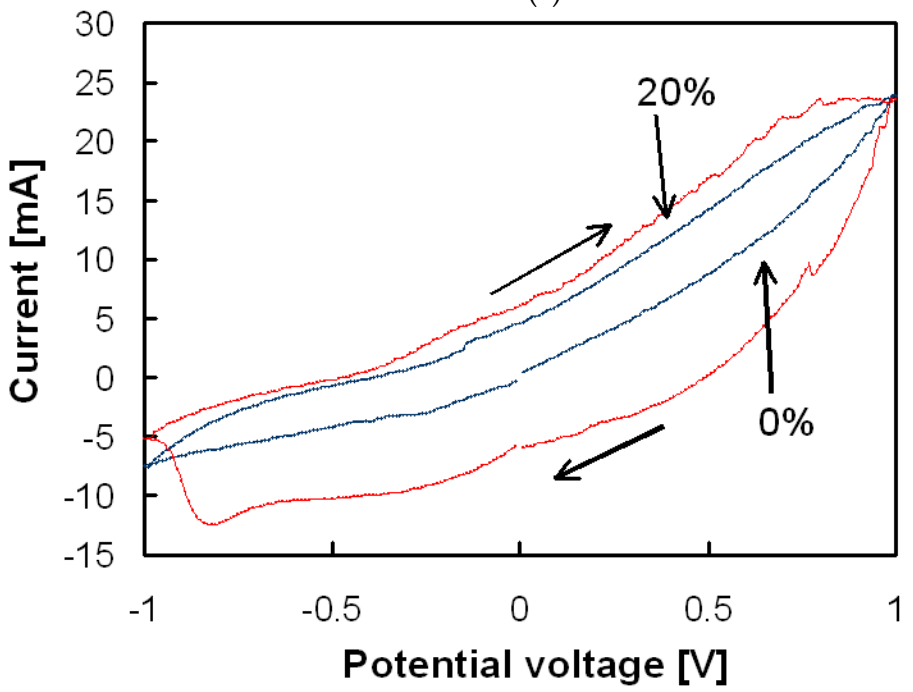

(b)

Fig. 3.3. (a) Relationships between potential voltage applied on PPy actuators and the strain in the LiTFSI solutions with 2-propanol concentrations of 0 and $20 \%$, and (b) the corresponding cyclic voltammograms of the PPy actuators and the strain in the LiTFSI solutions with 2-propanol concentrations of 0 and $20 \%$. 


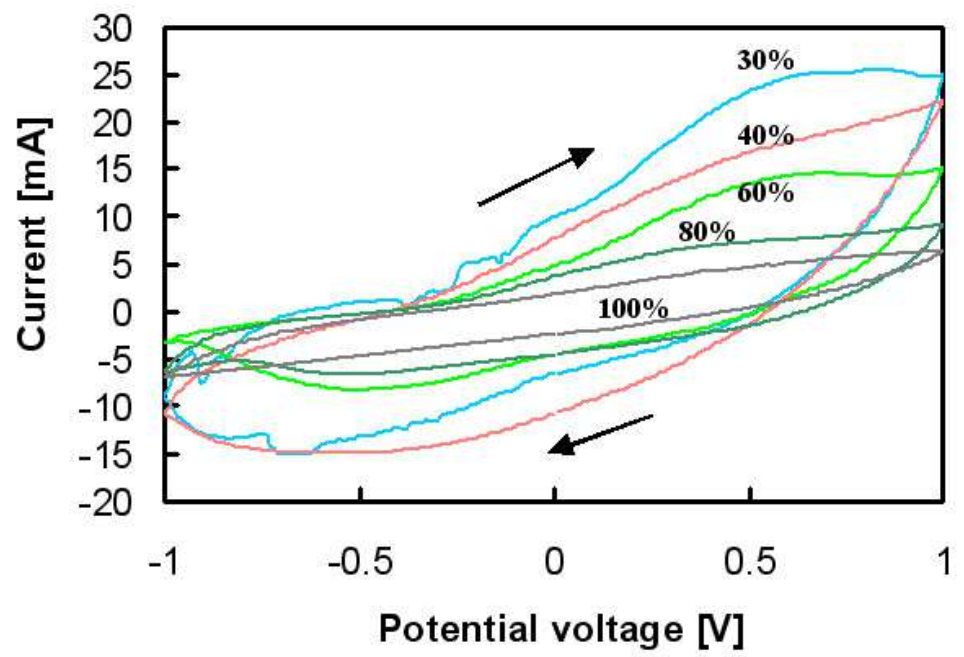

Fig. 3.4. Cyclic voltammograms for deformations in electrolyte solutions of LiTFSI mixed with 2-propanol concentrations of 30, 40,60, 80, and 100\%.

Hara et al. reported that their TFSI-doped PPy actuators exhibited the maximum deformation when their aqueous LiTFSI electrolyte solution contained $20-40 \%$ of propylene carbonate (Hara et al., 2005). They pointed out that these phenomena were due to the swelling of the PPy film with propylene carbonate. The PPy film was reported to have porous and sponge-like structures, and the swelling of the film increased the porous spacing. This will make the anions more easily penetrate into the PPy film, which results in the increase in the deformation of the PPy actuators.

It should be pointed out that the PPy actuators investigated in this research showed smaller levels of the creep effects in the electrolyte solutions containing 20-40\% 2-propanol while they showed the maximum deformation range. This could not be always explained only by the swelling of the PPy films. It is speculated that the surface tension and viscosity of water and 2-propanol affect the electrochemical deformation of the PPy actuators. Table 2 compares the surface tension and viscosity of pure water and 2-propanol at $20{ }^{\circ} \mathrm{C}$. The data were taken from the web page of the National Institute of Standards and Technology (NIST). The surface tension of 2-propanol is 21.7 dyn. $\mathrm{cm}^{-1}$, which is nearly $30 \%$ that of water. Therefore, when the PPy actuator is positively biased, TFSI- anions along with 2-propanol molecules might more easily penetrate into the porous structure of PPy. Thus, the increased deformation was observed for the 2-propanol concentration range between 20 and $40 \%$. On the other hand, the contraction of the PPy actuator was disturbed in the electrolyte solutions with the 2-propanol concentrations larger that $60 \%$. The TFSI- ions diffused into the PPy porous structure in the positive potential region could be disturbed to escape from the PPy structures due to 2-propanol's high viscosity nature in the negative potential region.

The mechanisms for these behaviors still need to be more carefully investigated. However, the introduction of optimised amounts of 2-propanol into the LiTFSI electrolyte solution significantly improves the deformation ranges of the PPy actuators. 


\begin{tabular}{|c|c|c|}
\hline & Surface tension $($ dyn.cm-1) & Viscosity (mPa.s) \\
\hline Water & 72.8 & 1.01 \\
\hline 2-propanol & 21.7 & 2.37 \\
\hline
\end{tabular}

Table 2. Comparison of surface tension and viscocity for water and 2-propanol at $20 \mathrm{oC}$ (data taken from the web page of the National Institute of Standards and Technology (http://webbook.nist.gov/chemistry/fluid/).

\subsection{Conclusions}

Soft actuators were fabricated by galvanostatic electropolymerization of the polypyrrole (PPy) thin film using a methyl benzoate electrolyte solution of N,N-diethyl-N-methyl-N-(2methoxyethyl)ammonium bis(trifluoromethanesulfonyl)imide. The electrochemical deformation behaviors of the PPy actuators were investigated in the aqueous solutions of an electrolyte, lithium bis(trifluoromethanesulphonyl)imide (LiTFSI), mixed with various concentrations of 2-propanol. The potential voltage range given to the actuators was between -1 and $1 \mathrm{~V}$ with a sweeping rate of $10 \mathrm{mVs}^{-1}$, and a stress of $0.3 \mathrm{MPa}$ was applied. The actuator exhibited nearly $3 \%$ of the electrochemical strain in the electrolyte solution without 2-propanol, and exhibited an electrochemical strain of up to $12 \%$ in the electrolyte solutions with the 2-propanol concentration between 20 and $40 \%$. However, the reduction of the electrochemical strain and the acceleration of the creeping effect were observed when the actuators were deformed in the electrolyte solution with 2-propanol concentration of more than $60 \%$.

\section{Dynamic behaviors of polypyrrole actuators in electrolyte solution mixed with 2-propanol}

\subsection{Introduction}

Hoshino et al. tried to immerse TFSI-doped PPy films into several organic chemicals, and found that the PPy films showed notable swelling in 2-propanol. They reported that the PPy actuators showed the increased electrochemical strains in aqueous LiTFSI solutions containing 20 to $40 \%$ of 2-propanol as described in the previous section (Hoshino et al., 2011).

In this section, the dynamic electrochemical deformation characteristics of TFSI-doped PPy soft actuators under potential sweep rates between 10 and $25 \mathrm{mVs}^{-1}$ in aqueous LiTFSI solutions with different 2-propanol concentrations are reported.

\subsection{Experimental procedure}

\subsubsection{The experimental procedures were already described in the previous section. 4.3 Results and discussion}

Figure 4.1. shows the time dependences of the strain of the actuators, as measured by the displacement of the weight as a function of time under the load stress of $0.3 \mathrm{MPa}$. The strain in Fig. 4.1. was defined as the length change of the PPy actuators divided by the length prior to deformation. No potential voltage was given for the first $30 \mathrm{~s}$, and after that repeated voltage sweeps with a period of 400 seconds at the potential sweep rate of $10 \mathrm{mVs}^{-1}$ were applied to the PPy actuators. 


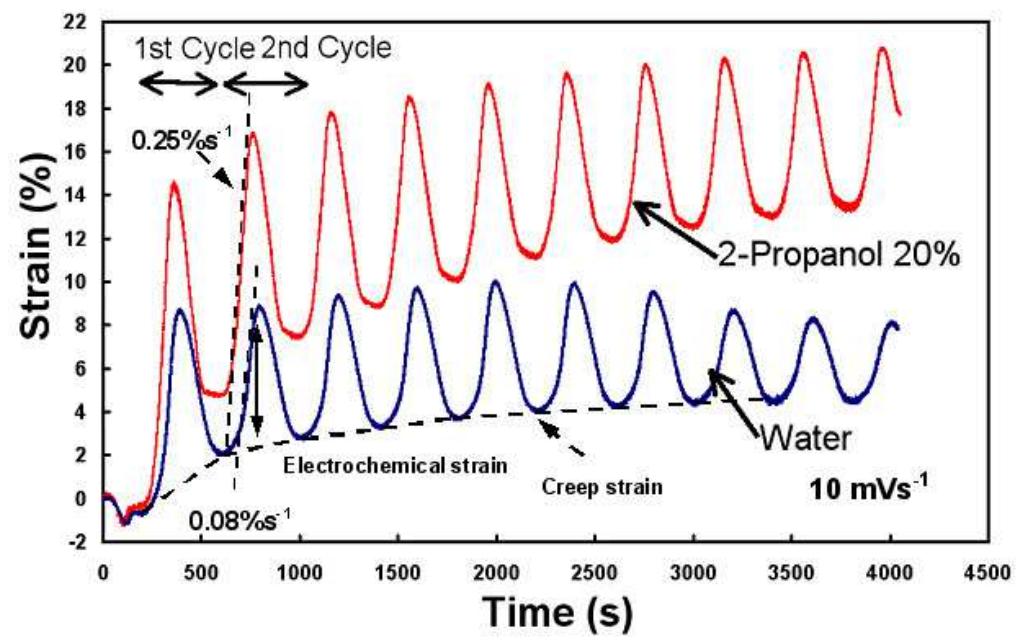

Fig. 4.1. Relationships between the strain of the actuator and time under the repeated operation of the actuator for 10 times with the potential sweep rate of $10 \mathrm{mVs}^{-1}$. The actuators were electrochemically deformed in aqueous solutions of $1 \mathrm{M}$ LiTFSI mixed with 2-propanol concentrations of 0 (water) and $20 \%$. The load stress during the deformation was $0.3 \mathrm{MPa}$.

The characteristics of the actuators were measured in aqueous solutions of LiTFSI with the different 2-propanol concentrations of 0 (water) and 20\%. During the initial $130 \mathrm{~s}$ of the first cycle, the PPy actuators immersed in the electrolyte solutions with the 2-propanol concentrations of 0 and 20\% showed slight reduction of the PPy length. Here, it should be noted that the strain of the measured PPy actuator consists of the electrochemical strain caused by anion motions and the swelling (creep) strain. Therefore, the electrochemical strain was defined by the difference of the peak value minus the lowest values of the strain for each potential cycle. The electrochemical strain of the PPy actuator driven in the $0 \% 2$ propanol electrolyte for the second cycle exhibited nearly $7 \%$. In contrast, the electrochemical strain of the PPy actuator driven in the aqueous solution of LiTFSI containing $20 \%$ of 2 -propanol was $12 \%$. In this case, the electrochemical strain of the PPy actuator gradually decreased after the repeated potential cycles but it stayed around 10\%, while the creep strain of the actuators continuously increased. This creep strain of the PPy actuator in the 20\% 2-propanol electrolyte was larger than that in the $0 \%$ 2-propanol (water) electrolyte. This seems to suggest that the creep strain is larger in the former case due to the swelling of the PPy film in 2-propanol. These creep behaviors look similar to creep effects in metal deformation processes. Sendai et al. recently reported in their detailed study on creep effects of PPy actuators, and concluded that this elongation could be recovered by releasing the stress during the deformation (Chida et al., 2010). Hence, they called this phenomenon the memory effect. The dotted straight lines correspond to the tangents of the second peaks, and the tangential slopes correspond to the electrochemical strain rate of $0.25 \% \mathrm{~s}^{-1}$ for the actuator in the $20 \%$ 2-propanol electrolyte and $0.08 \% \mathrm{~s}^{-1}$ for the actuator in the $0 \%$ 2-propanol (water) electrolyte, respectively. 
It is interesting to investigate whether the response time of the PPy actuator improves when the potential sweep rate is increased. Figure 4.2. shows the potential sweep rate dependences of the electrochemical strain of the PPy actuators in the electrolyte solutions with 0 and 20\% 2-propanol. The electrochemical strains continuously decreased with the sweep rate. The electrochemical strain of the PPy actuator in the electrolyte solution with $20 \%$ 2-propanol is larger than those in the electrolyte solution with $0 \%$ 2-propanol in the sweep rate range between 10 and $25 \mathrm{mVs}^{-1}$.

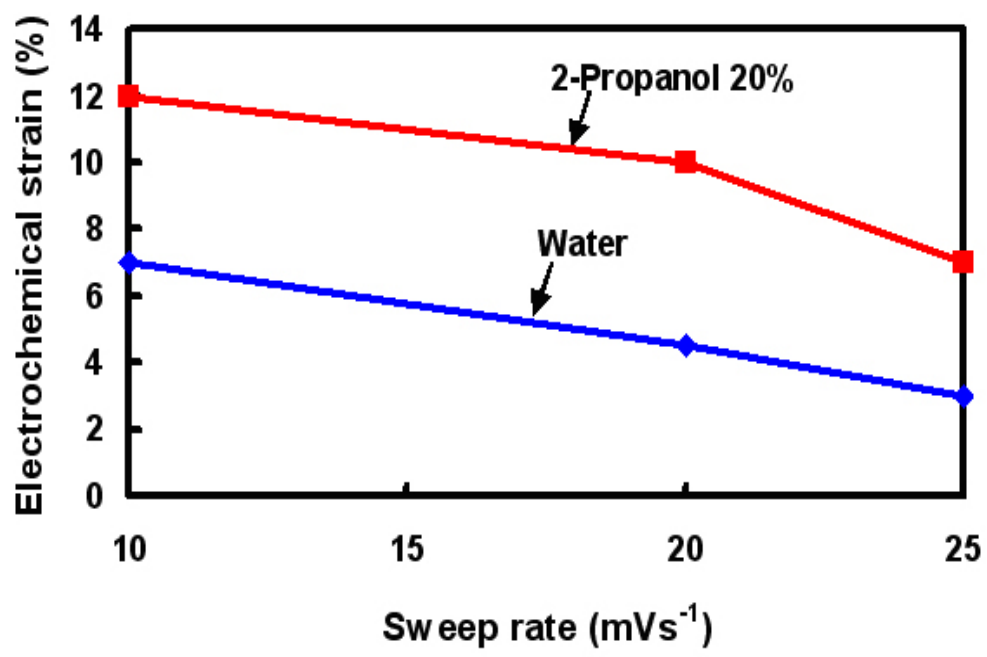

Fig. 4.2. Sweep rate dependences of electrochemical strains for PPy actuators in LiTFSI solutions with 2-propanol concentrations of 0 (water) and $20 \%$.

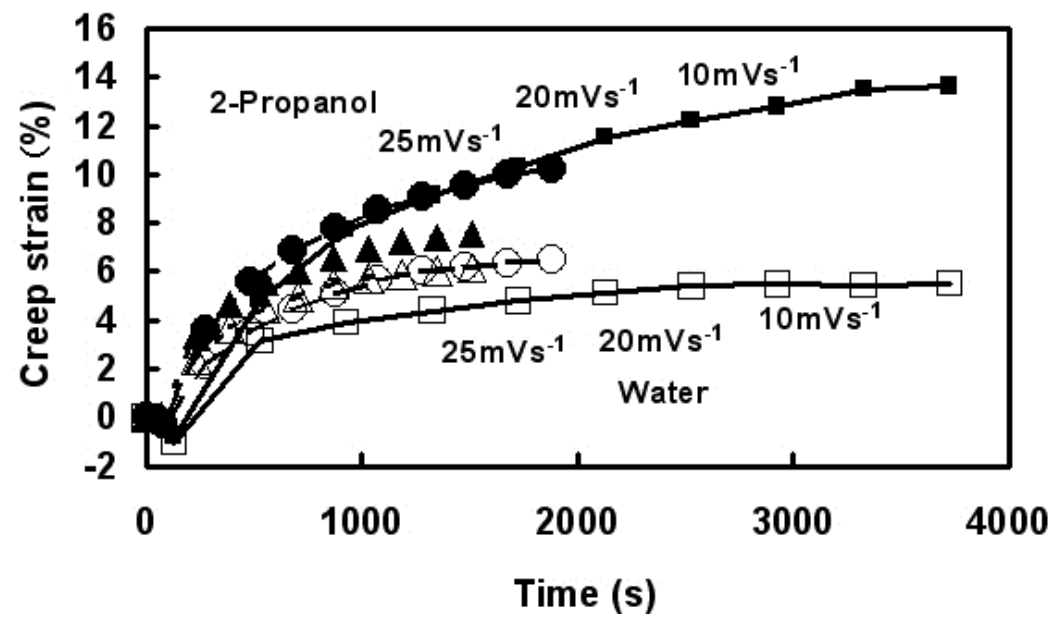

Fig. 4.3. Comparison of creep strains for PPy actuators driven in LiTFSI solutions of 0 (water) and $20 \%$ of 2-propanol with different potential sweep rates. 
Figure 4.3. shows the relationships between the creep strains and time of the PPy actuators driven in the electrolyte solutions with the different potential sweep rates. The time dependences look similar, which possibly suggests that the creep strain of the PPy actuators mostly depends on time but not on the potential sweep rate. This may mean that the PPy films swell both in the water and 2-propanol water solutions, and that the swelling of the PPy is larger in the 2-propanol electrolyte solution. This situation is more clearly described in Fig. 4.4. Figure 4.4. shows the potential sweep rate dependence of the creep strain measured at the time of $1000 \mathrm{~s}$. The creep strains are mostly determined by the time under the $0.3 \mathrm{MPa}$ stress.

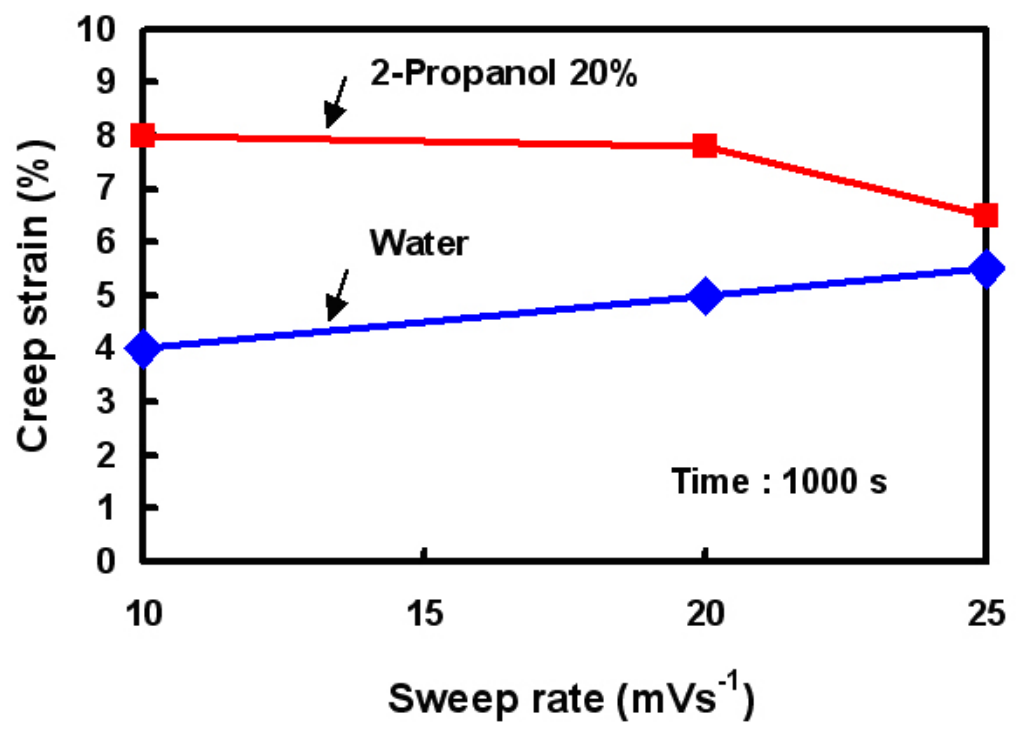

Fig. 4.4. Sweep rate dependences of creep strains for PPy actuators in LiTFSI solutions with 2-propanol concentrations of 0 (water) and $20 \%$.

Figure 4.5. shows the potential sweep rate dependences of electrochemical strain rate of the PPy actuator in the electrolyte solution containing 0 and $20 \%$ of 2-propanol. The electrochemical strain evidently is independent of the potential sweep rate, and those for the electrolyte solution with $20 \%$ 2-propanol are always larger than those for the electrolyte solution with $0 \%$ 2-propanol. If the ionic flow rate in the electrolyte solution influences the electrochemical strain, the electrochemical strain rate should be dependent on the potential sweep rate. This is because the potential sweep rate should modify the ionic flow rate in the electrolyte solution. Since this is not the case, another mechanism should be considered in the PPy actuator functions. Hara et al. reported that their TFSI-doped PPy actuators exhibited the maximum deformation when their aqueous LiTFSI electrolyte solution contains 20 to $40 \%$ of propylene carbonate (Hara et al., 2005). They pointed out that these phenomena were due to the swelling of the PPy film with propylene carbonate. The PPy film was reported to have porous and sponge like structures, and the swelling of the film 
increased the porous spacing. This will make the anions more easily penetrate into the PPy film, which resulted in the increase of the deformation of the PPy actuators.

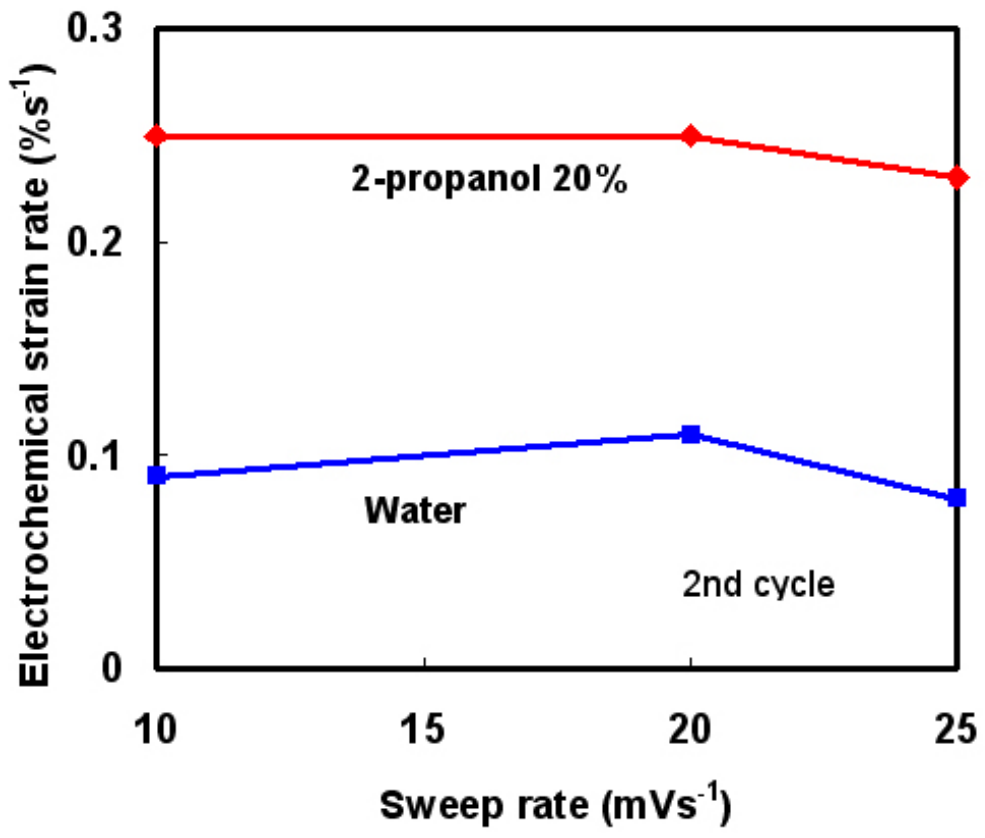

Fig. 4.5. Sweep rate dependences of electrochemical strain rates for PPy actuators in LiTFSI solutions with 2-propanol concentrations of 0 (water) and $20 \%$.

\subsection{Conclusion}

The influences of the potential sweep rate on electrochemical and creep strains PPy actuators in aqueous LiTFSI electrolyte solutions with 2-propanol concentrations of 0 and $20 \%$ were compared under the load stress of $0.3 \mathrm{MPa}$. The electrochemical strain rates in the 0 and 20\% 2-propanol solution were found to be approximately $0.1 \% \mathrm{~s}^{-1}$ and $0.25 \% \mathrm{~s}^{-1}$, respectively, and they are nearly independent of the sweep rate between 10 and $25 \mathrm{mVs}^{-1}$. These results suggest that the TFSI anion penetration into the PPy films might be limited by the interactions between the electrolyte and the PPy surface, and the reduced viscosity in the LiTFSI electrolyte solution containing 2-propanol possibly enhances the doping and dedoping of TFST anions along with the swelling effect of the PPy film by 2-propanol. The creep rate was more rapidly increased as time elapsed in the electrolyte solution containing $20 \%$ 2-propanol, which was due to the swelling of PPy film in the electrolyte.

\section{Comparison of polypyrrole organic thin film actuators with or without silicon microspring}

\subsection{Introduction}

Recently, Ding et al. reported a new type of PPy actuator that had a tubular geometry and a helical wire interconnect (Ding et al., 2003). The actuator was fabricated by forming a PPy 
film on a platinum wire ( $125 \mu \mathrm{m}$ in diameter) that was wrapped around with thinner $(25 \mu \mathrm{m}$ in diameter) platinum wire. A maximum strain of $5 \%$ and the response of $10 \% \mathrm{~s}^{-1}$ were achieved. A similar structure to minimize the response time of PPy actuators was also reported by Hara et al. (Hara et al., 2003, 2004a, 2004b). They deposited a PPy film on a tungsten helical coil $(250 \mu \mathrm{m}$ in diameter) made of a tungsten wire with a diameter of $30 \mu \mathrm{m}$. This fibrous PPy actuator exhibited a strain of $11.6 \%$ under the load of $0.2 \mathrm{~N}$. The tungsten wire also helped to reduce the potential drop within the PPy for the improved performance. Another trial to increase the extension and contraction ratios employing a corrugated PPy structure has been reported (Morita et al., 2010), and a bimorph structure of a PPy actuator for more uniform bending has also been reported (Chida et al., 2010).

In contrast, we considered applying these PPy soft actuator techniques to the actuation of the very small mechanisms used in silicon microelectromechanical systems (MEMS). To the best of our knowledge, there have been very few applications of these techniques to the actuation of small MEMS mechanisms (Chida et al., 2010, Guo et al., 1996, Hutchison et al., 2000). In this section, two kinds of PPy thin film actuators with or without a silicon MEMS microspring were fabricated and compared.

\subsection{Linear actuator design}

Figure 1 describes the designed actuator. The silicon microspring has a width of $0.5 \mathrm{~mm}$, length of $15 \mathrm{~mm}$, and thickness of $60 \mu \mathrm{m}$. The microspring consists of silicon wires having a cross-section of $10 \times 60 \mu \mathrm{m}^{2}$. The surface of this microspring is covered by a $91 \mu \mathrm{m}$-thick PPy

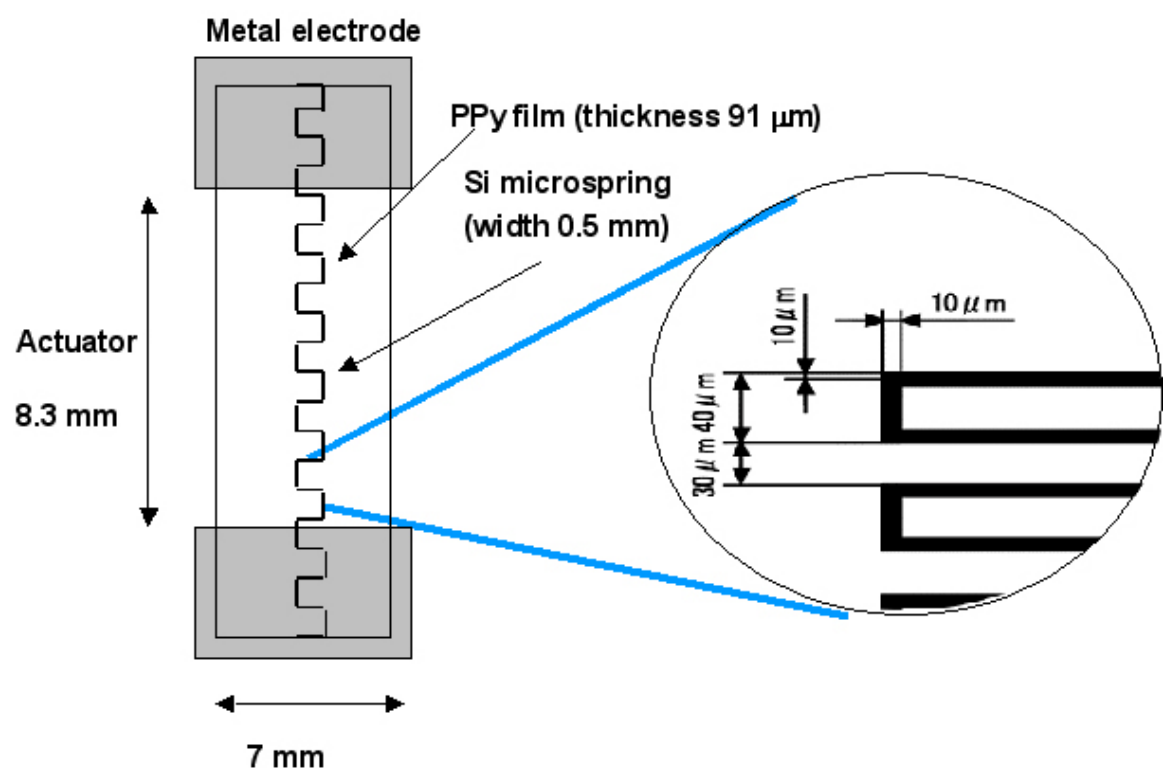

Fig. 5.1. Design of the PPy-driven silicon linear actuator; (a) corresponds to designed silicon micro spring, and (b) corresponds to the designed linear actuator driven by PPy expansion and contraction motions. 
film of length and width $15 \mathrm{~mm}$ and $7 \mathrm{~mm}$, respectively. The PPy film covering the microspring shrinks and expands along with the PPy film beside the microspring, which causes the actuation of the microspring. The top and bottom parts of the actuator were clipped with metal electrodes. As a result, the working area of the actuator was $8.3 \mathrm{~mm}$ in length and $7 \mathrm{~mm}$ in width. A PPy actuator with the same dimensions without the silicon MEMS micro spring was also fabricated for comparison.

\subsection{Actuator fabrication processes}

Figure 5.2. describes the fabrication processes of the microactuator. First, an extremely thin $(60 \mu \mathrm{m})$ silicon film was anodically bonded to a glass substrate of $1.5 \mathrm{~mm}$ in thickness (a). Next, the silicon microspring pattern was photolithographycally defined on the silicon film, followed by silicon etching using an inductively coupled plasma (ICP) dry etcher (b). The silicon microspring was released by immersing the structure in a buffered HF solution (c). The microspring was placed on an acrylic board, and a $100 \mathrm{~nm}$-thick Au film was sputter deposited on the whole surface of the microspring and the acrylic board (d). Finally, the PPy film with a thickness of approximately $91 \mu \mathrm{m}$ was electrochemically deposited on the whole surface of the sputtered $\mathrm{Au}$ film, and the structure was peeled off from the acrylic board in acetone (e).

The polymerization was done using a computer-controlled potentio-galvanostat (Hokuto Denko HZ-5000). A counter electrode (Ti), a reference electrode $(\mathrm{Ag} / \mathrm{AgCl})$, and a working electrode $(\mathrm{Au})$ were immersed into a solvent containing pyrrole monomers and an electrolyte, and the potential voltage was controlled to keep a constant current between the counter electrode and the working electrode of the Au surface covering the silicon microspring during the PPy polymerisation. The electropolymerization of PPy was done in a methyl benzoate solution with a volume of $50 \mathrm{ml}$ in which pyrrole monomers with a concentration of 0.25 mol.dm $\mathrm{m}^{-3}$ and the electrolyte tetra-n-butylammonium bis(trifluoromethansulfonyl)imide (TBATFSI) with a concentration of $0.2 \mathrm{~mol} . \mathrm{dm}^{-3}$ are dissolved. The polymerization was done at a constant current density of $0.2 \mathrm{~mA} . \mathrm{cm}^{-2}$ for $4 \mathrm{~h}$ at room temperature. The PPy film deposited on the Au surface was peeled off, and cut into the actuator dimension of $7 \times 15 \mathrm{~mm}^{2}$ as shown in Fig. 5.3b. The PPy actuator without the Si microspring of $7 \times 15 \mathrm{~mm}^{2}$ was also cut from the same PPy film. The thickness of the plane part of the PPy film was measured to be approximately $91 \mu \mathrm{m}$ using a micrometer. The measured electro conductivity of the PPy film was approximately $12 \mathrm{Scm}^{-1}$. In the previous publications, fairly large strain and fast response of PPy actuators, that were polymerized electrochemically with TBATFSI at the temperature of -10 oC, were reported (Hara et al., 2005a, 2004b). Therefore, the PPy actuators fabricated using (TBATFSI) were focused in this research.

Figure 5.3. shows the optical microscope image of the fabricated actuator taken from the backside (substrate side) of the actuator. The Au film in the plane PPy area was unintentionally peeled off from the PPy film during the actuator peeling off process in acetone, while the Au film covering the silicon microspring was not peeled off. Figure 5.4a. and 5.4b. show scanning electron microscope (SEM) images of the PPy actuator observed from the surface of the micro spring (electrolyte solution side) and the backside of the micro spring, respectively. It was indicated that the PPy film almost covered the silicon spring surface, and it had a rugged surface structure. Similar rugged structures were observed in the image taken from the backside. It is believed that this sponge-like structure is the origin of the large expansion and contraction ratios during the ion doping and dedoping processes. 
The space between the microsprings was not filled with the PPy film. This may mean that the polypyrrole film on the microspring does not contribute the extension and contraction of the silicon actuator. Therefore, it was determined that the actuation was realized utilizing the extension and contraction of the plane PPy film deposited beside the microspring.

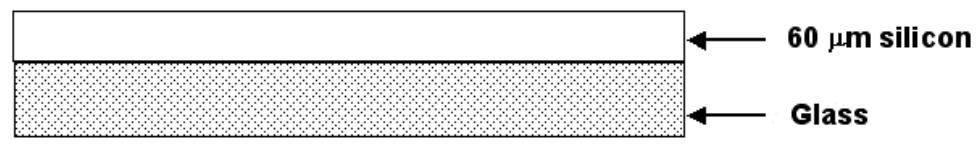

(a) Anodic bonding of $60 \mu \mathrm{m}$ silicon on glass substrate

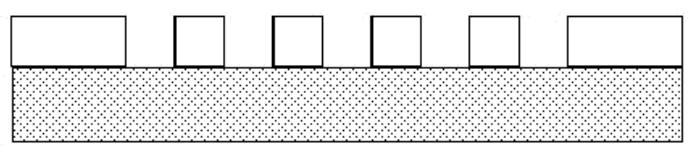

(b) Photolithography and ICP etching of silicon

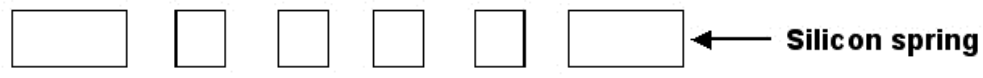

(c) Release of microspring structure using HF

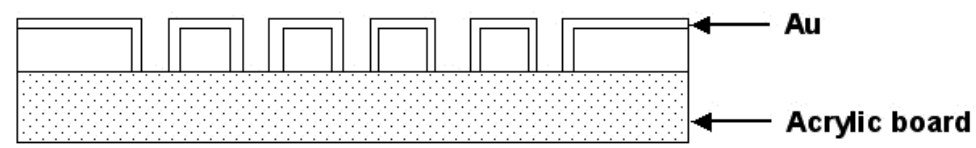

(d) Placing microspring on acrylic board and sputter deposition of Au film

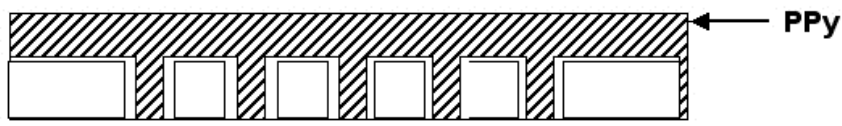

(e) PPy electrochemical deposition and release from acrylic board

Fig. 5.2. Cross- sectionally described linear actuator fabrication processes

\subsection{Characterizations}

The actuator characterization system that utilizes a balance to measure the expansion and contraction ratios under the load stress has already been described in Fig. 2.4. The PPy actuator was used as the working electrode in the lithium bis(trifluoromethansulfonyl)imide (LiTFSI) electrolyte solution of $1 \mathrm{~mol}^{\mathrm{dm}}{ }^{-3}$, and both of the PPy actuator ends were 


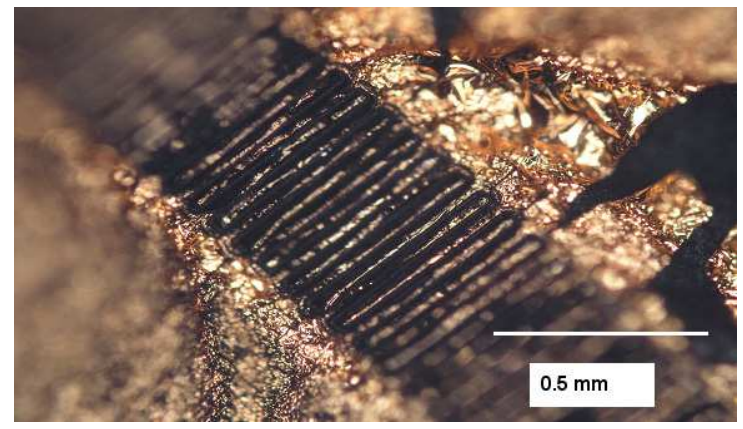

Fig. 5.3. Optical microscope image of the fabricated actuator taken from the backside (substrate side) of the actuator. The Au film in the plane PPy area was peeled off, while the Au film covering the silicon micro spring was not peeled off.
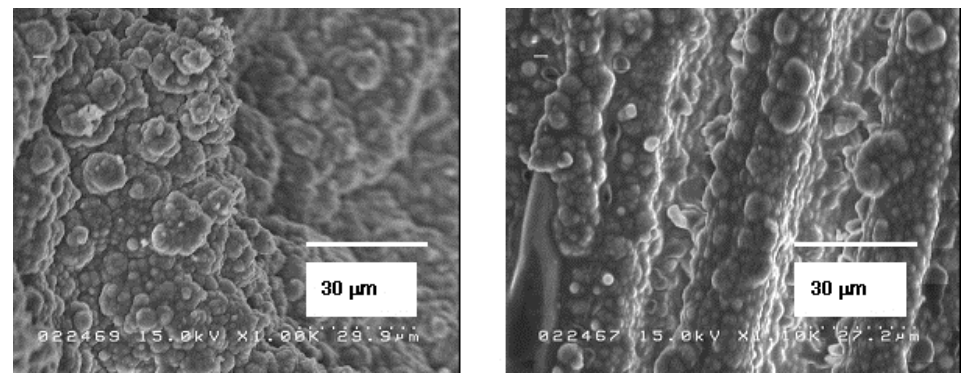

Fig. 5.4. Electron microscope (SEM) images of the PPy actuator observed from the surface (electrolyte solution side) of the micro spring (a) and backside (substrate side) of the micro spring (b).

suspended by metal clips. The size of the moving part of the PPy actuators was $7 \mathrm{~mm}$ in width, $8.3 \mathrm{~mm}$ in length, and $91 \mu \mathrm{m}$ in thickness. The PPy actuator exhibited the expansion and contraction motions under the alternating potential with the triangular wave shape applied between the PPy actuator and the counter electrode. The potential voltage difference between the PPy actuator and the electrolyte solution was monitored using an $\mathrm{Ag} / \mathrm{AgCl}$ reference electrode. The peak values of the potential voltage were -1 and $+1 \mathrm{~V}$, and the potential sweep rate was $10 \mathrm{mVs}^{-1}$. The extension and contraction of the PPy actuator was measured by monitoring the displacement of the weight position using the laser displacement sensor. An arbitrary load stress was applied on the PPy actuator by putting weights on the saucer of the balance. The weights used here were $0.05,0.2$, and $0.5 \mathrm{~N}$. The load stresses for these weights correspond to $0.07,0.3$, and $0.76 \mathrm{MPa}$, respectively.

Figure 5.5. shows the time dependences of the displacement (length change) of the actuators as measured with different weights of (a) $0.05 \mathrm{~N},(\mathrm{~b}) 0.2 \mathrm{~N}$, and (c) $0.5 \mathrm{~N}$ for the initial period of 800 seconds. Those weights correspond to $0.07,0.3$ and $0.76 \mathrm{MPa}$, respectively. The displacement vs. time curve for the eight of $0.05 \mathrm{~N}$ [Fig. 5.5a] seems to consist of two components of the electrochemical strain caused by the anion doping/dedoping processes and the creeping strain possibly due to the swelling of the PPy film. Here, the peak height was subtracted by the creeping strain and as shown in Fig. 5.5a, and the subtracted peak 

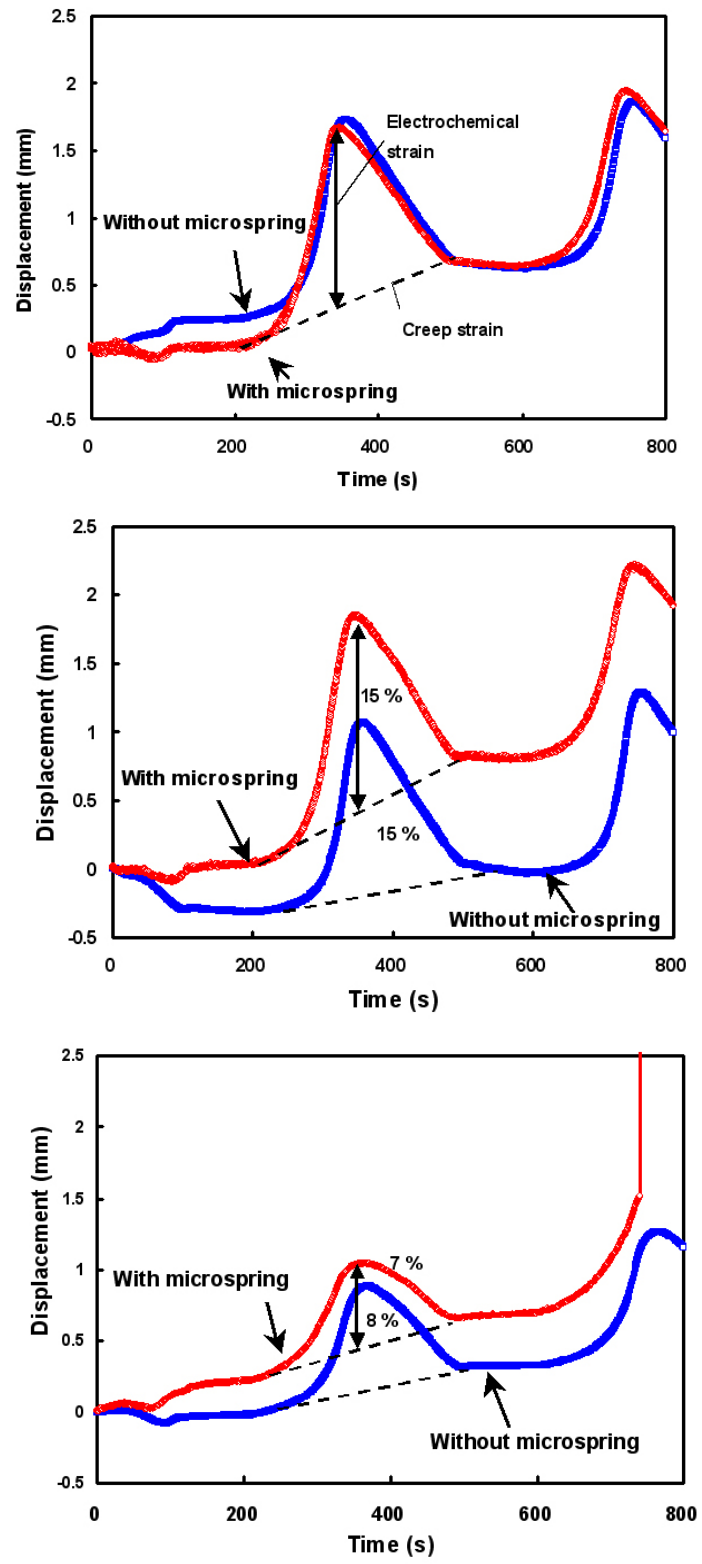

Fig. 5.5. Time dependences of the displacement (length change) of the actuators as measured with different weights of (a) $0.05 \mathrm{~N}$, (b) $0.2 \mathrm{~N}$, and (c) $0.5 \mathrm{~N}$ for the initial period of 800 seconds. Those weights correspond to $0.07,0.3$ and $0.76 \mathrm{MPa}$, respectively. 
height value was divided by the initial length of the actuator to define the electrochemical strain. In this case of the weight of $0.05 \mathrm{~N}(0.07 \mathrm{MPa})$, the electrochemical strains of the PPy actuators with or without the silicon microspring are nearly identical. In contrast, when the weight increased up to $0.2 \mathrm{~N}(0.3 \mathrm{MPa})$, the creeping strain of the PPy actuator with the silicon microspring increased notably, while the electrochemical strains of two actuators are nearly identical as seen in Fig. 5.5b. When the $0.5 \mathrm{~N}(0.76 \mathrm{MPa})$ was applied, both of the actuators showed the smaller electrochemical strains of approximately $7-8 \%$. In addition, the PPy actuator with the microspring torn off while the PPy actuator without the microspring did not tear off. The optical microscope observation of the torn off actuator showed cracks at the spring/PPy interface. The reason for the reduced electrochemical strain in the high load stress is not clear. The stressed polymer networks might possibly block the volume expansion caused by penetration of anions.

Figure 5.6. shows the repeated operation of the actuator for 15 times. The displacement of the actuators gradually increased due to creeping, while the electrochemical strains of them slightly decreased. The actuator with the microspring continued to have the electrochemical strain of $13 \%$, while the actuator without the microspring continued to have that of $15 \%$. The creeping effect of the PPy actuator with the silicon microspring was larger than the PPy actuator without the silicon microspring. Although the PPy actuator with the silicon microspring had slightly degraded performances compared to the PPy actuators without the silicon microspring, it will be beneficial for MEMS applications because of its large stress and strain.

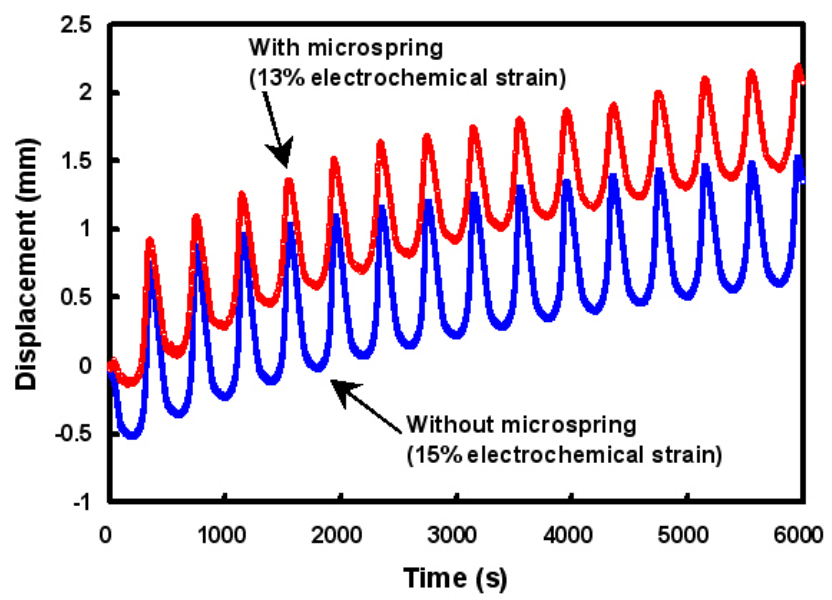

Fig. 5.6. Relationships between the displacement of the actuators and time under the repeated operation of the actuator for 15 times. The load weight was $0.2 \mathrm{~N}$ that corresponds to $0.3 \mathrm{MPa}$ stress.

The length of the actuator continues to increase as time elapses. This behavior looks similar to the creeping effect in metal deformation processes. Zama and others recently reported on their detailed study for this creeping effect of PPy actuators, and concluded that this elongation could be recovered by releasing the stress during the deformation (Zama et al., 
2005a, 2005b, Sendai et al., 2009). Although the actuator investigated here exhibited a slow response, the generating stress of the order of $0.3 \mathrm{MPa}$ is relatively large as an actuating mechanism for MEMS actuation. The PPy actuator requires an electrolyte solution during actuation. Therefore, some protecting film such as an artificial skin to cover the electrolyte solution surrounding the PPy actuator may be needed for actual MEMS applications.

\subsection{Conclusion}

Two kinds of PPy thin film actuators with or without the silicon MEMS microspring were fabricated and compared. The polypyrrole thin films with the thickness of $91 \mathrm{~m}$ were deposited by galvanostatic electropolymerization of a polypyrrole thin film using a methyl benzoate electrolyte solution of tetra-n-butylammonium bis(trifluoromethansulfonyl)imide (TBATFSI). One of the actuators was inserted with the silicon MEMS microspring with the length of $15 \mathrm{~mm}$, the width of $0.5 \mathrm{~mm}$, and the thickness of $60 \mu \mathrm{m}$. The MEMS PPy actuator exhibited nearly $12 \%$ of the electrochemical strain under the load of $0.2 \mathrm{~N}$ in a water solution of an electrolyte, lithium bis-trifluoromethane sulphonyl imide (LiTFSI) at the bias sweep rate of $10 \mathrm{mVs}^{-1}$ in the voltage range between -1 and $1 \mathrm{~V}$. The load stress was approximately $0.3 \mathrm{MPa}$. Although the performances of the MEMS actuators showed some degradation compared to the PPy actuator without the MEMS microspring, the MEMS PPy actuator may be beneficial to drive MEMS structures, which require a large strain and a large stress with a low voltage actuation.

\section{Acknowledgements}

The author express heartfelt applications to his collaborators, Mr. Hiroyuki Katsumata, Mr. Takayuki Fujiya, Mr. Daiki Hoshino, Mr. Tsuyoshi Morita, Mr. Yutaka Chida, Mr. Zongfan Duan, Mr. Yutaro Suzuki, Mr. Shou Ogihara, Mr. Syota Kaihatsu, Mr. Masahiro Higashi, and other students. The staffs of the Micro Functional Device Research Center are also appreciated.

\section{References}

Baughman, R.H. (1996). Synth. Met., 78, 339.

Chida, Y., Morita, T., Machida, R., Hoshino, D., \& Nishioka, Y. (2010). Mol. Cryst. Liq. Cryst., 519, 115.

Guo, S., Fukuda, T., Kosuge, K., Arai, F., Oguro, K., \& Negura, M. (1996). Transactions of the Japan Society of Mechanical Engineers, C62(596), 1384.

Han G., \& Shi, G. (2004). Sensors and Actuators, B 99, 525.

Hara, S., Zama, T., Takashima, W., \& Kaneto, K. (2004). J. Mater. Chem., 14, 1516.

Hara, S., Zama, T., Ametani, A., Takashima, W., \& Kaneto, K. (2004). J. Mater. Chem., 14, 2724.

Hara, S., Zama, T., Takashima, W., \& Kaneto K. (2004). Polym. J., 36, 933.

Hara, S., Zama, T., Takashima, W., \& Kaneto, K. (2005). Synthetic Metals, 149, 199.

Hara, S., Zama, T., Takashima, W., \& KANETO, K. (2005). Smart Mater. Struct., 14, 1501.

Hara, S., Zama, T., Takashima, W., \& Kaneto, K. (2006). Synth. Met., 156, 351. 
Hoshino, D., Morita, T., Chida, Y., Duan, Z., Ogihara, S., Suzuki, Y., \& Nishioka, Y. (2011). Jpn. J. Appl. Phys. 50 (2011) 01BG10 .

Hutchison, A. S., Lewis, T. W., Moulton, S. E., Spinks G. M., \& Wallace, G. G. (2000). Synthetic Metals 113, 121.

Jager, E. W. H., Smela, E., Inganas O., \& Lundstrom, I. (1999). Synthetic Metals 102, 1309.

Morita, T., Chida, Y., Hoshino, D., Fujiya, T., \& Nishioka, Y. (2010). Mol. Cryst. Liq. Cryst. $519,121$.

Ogasawara, M., Funahashi, K., Demura, T., Hagiwara T., \& Iwata, K. (1986). Synth. Met., 14, 61.

Sendai, T., Suematsu, H., \& Kaneto, K. (2009). Jpn. J. Appl. Phys., 48, 51506.

Zama, T., Hara, S., Takashima, W., \& Kaneto, K. (2005). Bull. Chem. Soc. Jpn., 78, 506.

Zama, T., Hara, S., Takashima, W. \& Kaneto, K. (2005). Jpn. J. Appl. Phys., 44, 8153.

Zama, T., Hara, S., Takashima, W., \& Kaneto, K. (2005). Synth. Met., 149, 199. 


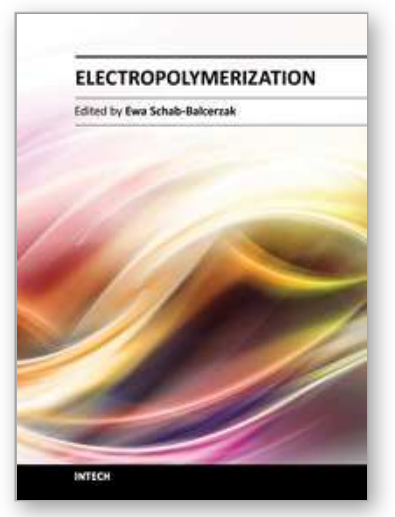

\author{
Electropolymerization \\ Edited by Dr. Ewa Schab-Balcerzak
}

ISBN 978-953-307-693-5

Hard cover, 214 pages

Publisher InTech

Published online 22, December, 2011

Published in print edition December, 2011

In recent years, great focus has been placed upon polymer thin films. These polymer thin films are important in many technological applications, ranging from coatings and adhesives to organic electronic devices, including sensors and detectors. Electrochemical polymerization is preferable, especially if the polymeric product is intended for use as polymer thin films, because electrogeneration allows fine control over the film thickness, an important parameter for fabrication of devices. Moreover, it was demonstrated that it is possible to modify the material properties by parameter control of the electrodeposition process. Electrochemistry is an excellent tool, not only for synthesis, but also for characterization and application of various types of materials. This book provides a timely overview of a current state of knowledge regarding the use of electropolymerization for new materials preparation, including conducting polymers and various possibilities of applications.

\title{
How to reference
}

In order to correctly reference this scholarly work, feel free to copy and paste the following:

Yasushiro Nishioka (2011). Polypyrrole Soft Actuators, Electropolymerization, Dr. Ewa Schab-Balcerzak (Ed.), ISBN: 978-953-307-693-5, InTech, Available from:

http://www.intechopen.com/books/electropolymerization/polypyrrole-soft-actuators

\section{INTECH}

open science | open minds

\author{
InTech Europe \\ University Campus STeP Ri \\ Slavka Krautzeka 83/A \\ 51000 Rijeka, Croatia \\ Phone: +385 (51) 770447 \\ Fax: +385 (51) 686166 \\ www.intechopen.com
}

\author{
InTech China \\ Unit 405, Office Block, Hotel Equatorial Shanghai \\ No.65, Yan An Road (West), Shanghai, 200040, China \\ 中国上海市延安西路65号上海国际贵都大饭店办公楼405单元 \\ Phone: +86-21-62489820 \\ Fax: +86-21-62489821
}


(C) 2011 The Author(s). Licensee IntechOpen. This is an open access article distributed under the terms of the Creative Commons Attribution 3.0 License, which permits unrestricted use, distribution, and reproduction in any medium, provided the original work is properly cited. 